\title{
Enquête
}

Archives de la revue Enquête

1 | 1985

À propos des cultures populaires

\section{Symbolisme dominant et symbolisme dominé}

\section{(2) OpenEdition}

1 Journals

Édition électronique

URL : http://journals.openedition.org/enquete/38

DOI : 10.4000/enquete.38

ISSN : 1953-809X

Éditeur :

Cercom, Éditions Parenthèses

Édition imprimée

Date de publication : 2 avril 1985

\section{Référence électronique}

"Symbolisme dominant et symbolisme dominé », Enquête [En ligne], 1 | 1985, mis en ligne le 03 juin

2013, consulté le 19 avril 2019. URL : http://journals.openedition.org/enquete/38 ; DOI : 10.4000/ enquete.38

Ce document a été généré automatiquement le 19 avril 2019 


\section{Symbolisme dominant et symbolisme dominé}

Contribution à la protohistoire de la réciprocabilité symbolique des rapports de force

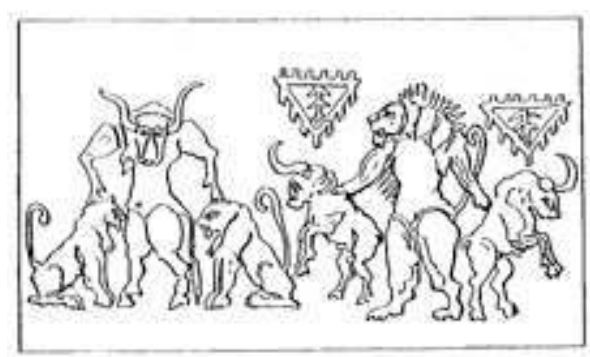

Empreinte de tablette proto-élamite (Suse, fin de période de Djemdet-Nasr) : taureau maîtrisant des lions, et lion maîtrisant des taureaux. Exercice préliminaire : trouver l'animal dominant.

1 J.-C. PASSERON.- Je voudrais, pour introduire à ce séminaire bifide, poser une question dont la simplicité est trompeuse, mais non perfide: le fait de travailler sur un objet comme les «cultures dominées » exige-t-il que la sociologie de la culture se donne des interrogations, des concepts, voire des méthodes spécifiques?

Il ne faut pas se récrier trop vite devant cette question, sous prétexte qu'en sa forme naïve elle pourrait sembler attentatoire à l'universalité de la science sociale, voire désobligeante pour les classes ou les groupes dominés : ne laisserait-elle pas soupçonner le pire? que, par exemple, l'analyse sociologique s'apprêterait, lorsqu'elle pénètre sur le terrain des cultures populaires, à redimensionner ses instruments à la mesure de leur " pauvreté » ou de leur pénurie symbolique ? Le procès d'intention en ethnocentrisme est vite instruit contre toute spécification de la sociologie des classes populaires : ne va-t-on pas à la constitution d'une sociologie $a d$ hoc du « petit », forme simplifiée de la sociologie du "grand ", qui s'en distinguerait comme le programme des petites classes se distingue à l'école de celui des grandes ? Ce cri du cœur - qui comme toute indignation vertueuse s'épuise à repousser des propositions dont il a évité de faire le tour - ne doit cependant pas nous arrêter. Ce n'est là que le premier mouvement du populisme auquel, je le crains, nous aurons constamment affaire dans le débat : s'il crie avant même qu'on ait touché à 
ses enfants d'adoption, c'est qu'il se fait un devoir de subordonner tout droit d'analyse à l'obtention préalable d'un brevet éthique de bienveillance ou à une déclaration liminaire d'intention admirative. Quand la morale s'en mêle, il faut pour conquérir le droit de décrire donner assez de signes que le cœur est du bon côté de la barricade. L'ennui c'est qu'ici les côtés changent facilement de côté. Comprenons que le souci de se donner un dispositif particulier de questionnement et de description peut tout aussi bien s'autoriser du soupçon inverse. La question s'énonce alors : la sociologie de la culture dont le langage théorique a stabilisé un certain nombre de concepts et de traits pertinents revendiquant implicitement la généralité sociale, n'a-t-elle pas, sans y prendre garde, proportionné ses instruments et réglé ses viseurs sur le seul cas de figure où le jeu symbolique tient son sens et ses règles de se jouer en situation dominante? Pareils instruments de description et d'intelligibilité ne risquent-ils pas quand on les applique tels quels à des pratiques culturelles trop éloignées de ce cas de figure, de réintroduire en même temps que leurs accommodations préalables sur la logique des cultures dominantes, quelque chose du regard ethnocentrique que toute culture dominante porte immémorialement sur une culture dominée? S'il veut résister à cette dérive qui condamne au misérabilisme une description des cultures dominées trop attachée aux instruments qu'elle a forgés pour l'étude des cultures dominantes, voilà le populisme obligé d'opérer sa révolution du pour au contre. Ce ne sera pas la dernière.

Oublions donc les préalables éthiques, ne serait-ce que pour éviter le tournis, posture Incommode à l'analyse sociologique et revenons à notre question.

Non sans la circonscrire d'emblée aux formes de domination qui s'exercent au sein d'une même société. La question de la domination symbolique pourrait en effet s'entendre aussi des rapports inégaux qui s'établissent entre sociétés globales - qu'il s'agisse de colonisation, de satellisation ou plus simplement d'hégémonie culturelle et linguistique. Même dans les rapports entre sociétés distinctes, le schéma de la domination culturelle (ou de l'échange symbolique inégal) permet en effet de décrire efficacement nombre de traits affectant aussi bien les intellectuels que les masses, les communautés scientifiques que les courants artistiques, les mœurs que les modes de raisonnement, bref tous les phénomènes qui procèdent de la soumission d'une périphérie à un centre (hérodianisme). Mais la restriction du problème aux rapports inégaux qui associent intimement groupes et classes d'une même société suffira à nous occuper parce qu'il conduit à une difficulté spécifique dont il faut prendre la mesure. C'est la difficulté propre à toute sociologie des cultures populaires, dont le "relativisme culturel»-principe théorique conçu pour redresser les torts faits à des sociétés lointaines - ne saurait fournir la clé. En l'occurrence, c'est le sens même du vecteur de la description qui est en cause et qui reste en suspens. Faut-il, pour comprendre une culture populaire dans sa cohérence symbolique, la traiter comme un univers significatif autonome, en oubliant tout ce qui est en dehors d'elle et au-dessus d'elle, et d'abord les effets symboliques de la domination que subissent ceux qui la pratiquent, quitte à y revenir après coup? Ou faut-il au contraire partir de la domination sociale qui la constitue comme culture dominée pour interpréter par rapport à ce principe d'hétéronomie toutes ses démarches et ses productions symboliques?

5 À propos de nations ou d'ethnies que l'histoire met en relations d'inter-action inégale, il est toujours possible de partir d'un bilan culturel dressé dans l'hypothèse de leur autonomie préalable pour en venir à décrire et à interpréter par référence à cet état premier « d'innocence » symbolique, les changements de sens et d'équilibre, les apports 
ou les amputations, les altérations ou les ré-interprétations que produit l'instauration de la relation inégale. On est commodément installé dans une problématique de « l'acculturation » ou du « contact de civilisation ». Il y a bien, en ce cas, un en-deçà de la domination: d'où le confort méthodologique de la démarche interprétative qui peut alors comparer deux configurations réelles pour soupeser par différence les effets produits par l'Instauration de la domination. Il n'y a, au contraire pas d'en-deçà historique des rapports inégaux entre classes ou groupes, mais seulement, lorsqu'on s'interroge sur leur passé et leur constitution, une configuration antérieure des rapports de domination, toujours-déjà noués même si c'est entre groupes définis différemment.

6 Le bilan d'une culture populaire qui se fonde sur l'hypothèse de son autonomie symbolique peut sans doute s'autoriser de la tendance de tout groupe social à organiser ses expériences en univers cohérent, tendance dont aucune condition sociale, fût-elle la plus malheureuse, ne peut empêcher complètement le travail de mise en ordre symbolique : même dominée une culture fonctionne encore comme une culture. C'est là le droit imprescriptible au symbolisme qu'accordait à tout groupe social la thèse wébérienne selon laquelle toute condition sociale est en même temps le lieu d'une organisation de la perception du monde social en un « cosmos de rapports dotés de sens ». Mais dans le cas d'une culture dominée, il faut savoir qu'on se condamne, pour faire fonctionner ce principe d'interprétation, à transformer une autonomisation méthodologique en autonomisation de principe. C'est un pari interprétatif, tout comme le pari inverse d'oublier son autonomie relative afin de ne manquer aucune interprétation de ses traits par rapport aux effets de la domination. L'un et l'autre paris engagent la question de savoir ce que la description du sens d'une culture populaire perd ou gagne au choix théorique d'ignorer quelque chose de sa réalité symbolique pour mieux appréhender ce qu'elle choisit d'en épuiser en le construisant systématiquement. La difficulté, on le voit, c'est que la perte ou le gain de chacun de ces paris descriptifs ne se mesure pas à une « réalité » univoque : l'ambivalence significative d'une culture dominée lui fera toujours avouer quelque chose de vrai lorsqu'on la mettra à la question de n'importe lequel de ces deux interrogatoires. Ce que perd un principe de description ne se mesure finalement qu'à ce que Vautre réussit à décrire. La sociologie des cultures populaires est un « jeu à somme nulle » où les bilans globaux ne s'équilibrent pas puisque chacune des deux stratégies sociologiques de description peut encaisser son gain sans consentir à apercevoir sa perte qui n'est comptabilisée que par le gain descriptif de la stratégie alternative. Sans parler de quelques autres difficultés : le gain ou la perte qu'enregistrent l'un ou l'autre choix ne sont sans doute pas les mêmes selon les classes dominées qu'on prend pour objet, selon leurs strates ou leurs sous-groupes; selon leurs pratiques non plus. Il vaut donc la peine de s'arrêter sur cette aporie théorique qui engage tous les problèmes de description empirique posés à la sociologie par l'usage d'un concept comme celui de "domination symbolique» lorsqu'elle l'applique à la description des classes populaires et de leur univers culturel.

7 Lorsqu'elle se tourne vers les cultures populaires, la sociologie de la culture n'est pas innocente, elle est déjà armée de théories ou au moins d'hypothèses sur le symbolisme social qui ont toutes quelque chose en commun. La sociologie de la culture a commencé, comme toute autre branche de la sociologie ou de l'histoire, à faire un sort à ce qui se donne à voir comme « important », comme « significatif » dans le champ de l'histoire des formes, des mécanismes de leur démarcation ou dans les manifestations de leur pouvoir social. C'est là-dessus qu'elle a réglé sa doctrine des structures et des fonctions 
symboliques. Les choix conceptuels qui commandent la description des conduites symboliques ainsi que les choix méthodologiques qui déterminent la technique d'observation (sélection des terrains de pratiques, catégorisation des différences, repérage des co-occurrences) portent toujours la marque des « objets » (c'est-à-dire des «traits pertinents») auxquels s'est insidieusement accoutumée une sociologie de la culture centrée - par dilection ou animadversion, peu importe - sur les pratiques les plus légitimes des groupes dominants ou des groupes intermédiaires qui réfèrent exclusivement leurs symbolismes à la reconnaissance sinon à la connaissance de la légitimité culturelle. Ces choix resteraient-ils par miracle pertinents pour décrire tout ce qu'il y a à décrire dans une culture populaire ? Ne risquent-ils pas, en imposant l'usage d'un index de symbolisation (ce qui est légitimement symbolique dans les classes dominantes) et d'un algorithme d'interprétation (la revendication concurrentielle de la légitimité culturelle) décrypteurs conçus pour d'autres enjeux symboliques, non seulement de faire négliger la description de symbolismes indexés différemment, mais encore pour les symbolismes mêmes que détecteront tant bien que mal des capteurs réglés sur un autre terrain, de les interpréter par référence à un autre principe que celui auxquels ils se réfèrent, fût-ce pour partie de leur sens?

8 Il ne suffit pas de répondre que mesurer une culture dominée à l'aune de la culture qui la domine est, en tout état de cause, exigible pour restituer à l'analyse sociologique tout ce qui agit dans la réalité sociale, en arguant, à juste titre, que les pratiquants d'une culture populaire se trouvent, qu'ils le veuillent ou non, qu'ils le sachent ou non, objectivement mesurés dans la réalité des rapports sociaux (à l'école comme dans les interactions les plus quotidiennes) aux critères de la culture dominante. Ou plutôt cette réponse doit d'abord être faite à ceux qui s'imagineraient naïvement qu'ils ne perdent rien en décrivant cultures populaires et cultures dominantes abstraction faite des rapports de force et de sens liant les groupes qui les pratiquent, comme si les classes d'une même société pouvaient jamais être aussi étrangères les unes aux autres que peuvent l'être des sociétés distinctes dont la rencontre inégale a toujours quelque chose de conjoncturel. Le relativisme culturel qui fait justice des contresens sur le sens des cultures colonisées ou lointaines, inspirés au colonisateur ou au "civilisateur " par son ignorance de la réalité des sociétés étrangères, ferait ici injustice interprétative aux classes populaires en choisissant d'ignorer dans la description de leur culture ce qui n'est jamais relativisé ni relativisable dans la réalité de leur condition, à savoir l'existence toujours proche et intime du rapport social de domination qui, même s'il n'est pas continûment à l'œuvre dans tous les actes de symbolisation effectués en position dominée, les marque culturellement, ne serait-ce que par le statut qu'une société stratifiée réserve toujours aux productions d'un symbolisme dominé. Le statut social d'un objet symbolique fait partie de la définition complète de son sens culturel. Le parti pris populiste peut bannir ce principe désagréable de ses descriptions, non de la réalité.

Mais une fois cela dit - qui oblige aux constats décrivant les caractéristiques qu'une culture populaire doit à la condition dominée dans laquelle elle est condamnée à s'exprimer, et qui conduit à décrire les attitudes et à mesurer les chances négatives que les membres des classes populaires doivent à leur culture vernaculaire lors de toute confrontation avec les exigences de la culture légitime - a-t-on tout décrit de ce que signifie une culture populaire et, en particulier, de ce qu'elle se signifie à elle-même, y compris quand elle s'illusionne sur son autonomie? Une illusion qui s'organise en système de pratiques, de langage et de symboles propose un objet réel à l'analyse 
culturelle. Ce n'est que pour Spinoza, non pour le sociologue, qu'il suffit d'en dire le néant énonciatif pour énoncer tout ce qu'elle dit: Durkheim, dans Les formes élémentaires de la vie religieuse, ne s'y trompait pas à propos d'une autre «illusion bien fondée » dont les effets sont loin d'être illusoires. Une illusion ne peut-être complètement comprise, admettonsle, que par référence au principe de réalité qu'elle élude (ici l'accord des barbes marxiennes, durkheimiennes et freudiennes est impressionnant); mais il faut aussi accepter de prendre au pied de la lettre la logique propre d'un fonctionnement symbolique - même si sa revendication d'autosuffisance est illusoire - pour rendre compte de la diversité et de la cohérence de ses productions (ici la barbe de Marx disparaît de la cohorte des garants, mais celle de Weber vient s'ajouter à celle de Freud). L'oubli de la domination n'est sans doute qu'un des principes de l'activité de symbolisation populaire mais c'est un principe que le sociologue ne saurait oublier ni confondre d'ailleurs avec celui de la dénégation ou de la contestation, encore moins avec celui de l'acceptation ou de la résignation, tous principes qui se réfèrent, eux, directement aux relations de domination. Nul ne peut évidemment décréter en lieu et place des pratiques des dominés les moments féconds de cet oubli et surtout pas le supposer constant ou omnipotent - comme le fait le populisme en jetant son pavé dans la mare théorique. Mais la sociologie a bien pour tâche d'y aller voir.

10 La question se précise donc en une autre, qui éveille en même temps une inquiétude sémantique : que veulent dire les qualificatifs de « dominant » et de « dominé » quand on les applique à des symbolismes (idées, cultures)? De ce qu'en sa conception marxiste (exploitation économique ou hégémonie politique) ou en sa conception wébérienne (rapport de commandement i.e. "chance» qu'un ordre soit obéi), le rapport de domination qui s'établit entre des groupes ou des individus nous soit à peu près clair, c'est-à-dire qu'il indique clairement au sociologue les faits sociaux qu'il a à décrire et à mesurer, s'ensuit-il que nous puissions utiliser sans autres précautions le concept de «domination », quand nous disons qu' « une culture en domine une autre»? Le rapport de «domination symbolique » se laisse-t-il saisir par les mêmes critères, les mêmes constats ? Produit-il des effets aussi univoques? Avons-nous ici les mêmes repères pour trancher du « commandement » ? Des « idées » commandent-elles à d'autres idées comme des hommes commandent à des hommes, même quand les unes sont les idées des hommes qui commandent et les autres les idées des hommes qui obéissent? Bref, des rapports entre symboles fonctionnent-ils dans la même logique que des rapports entre groupes ou individus?

11 Partons pour éclaircir cette question d'un schéma qui, je crois, hante toute description des relations entre cultures dominantes et cultures dominées. C'est, bien sûr, le schéma de Marx qui, en la matière, garde quelque chose de son pouvoir persuasif même chez ceux qui sa croient le moins marxistes. Il suggère en effet une solution commode du problème en effaçant toute différence entre rapports de force entre groupes et rapports de force entre idées. Il n'y a plus à décrire quels sont les mécanismes d'imposition symbolique et à interroger leurs éventuels décalages ou contre-effets par rapport aux mécanismes de la domination sociale puisqu'on se trouve dispensé d'interroger les rapports entre cultures lorsqu'on connaît les rapports entre les groupes qui en sont les supports. On voit que l'emploi de cette décalcomanie s'étend bien au-delà de l'affiliation marxiste: à preuve l'utilisation d'expressions tout-venant comme "discours dominants», "sociologie dominante", etc.., qui se réfèrent seulement au constat de la force (sociale ou économique) d'un groupe ou d'une institution. 
Chacun a en tête le paragraphe décisoire de L'Idéologie allemande où Marx martèle sa correspondance entre "puissance matérielle dominante» et "puissante spirituelle dominante »: "Les pensées de la classe dominante sont aussi à toutes les époques les pensées dominantes [...] Les idées (« des individus qui constituent la classe dominante ») sont les idées dominantes de leur époque $»^{1}$. Mais remarque-t-on assez que les phrases de Marx nous glissent, en même temps qu'un constat historique peu discutable à ce niveau de généralité, une homologie qui, elle, fait problème ou plutôt qui ferme avant de l'ouvrir un débat capital?

Schéma 1

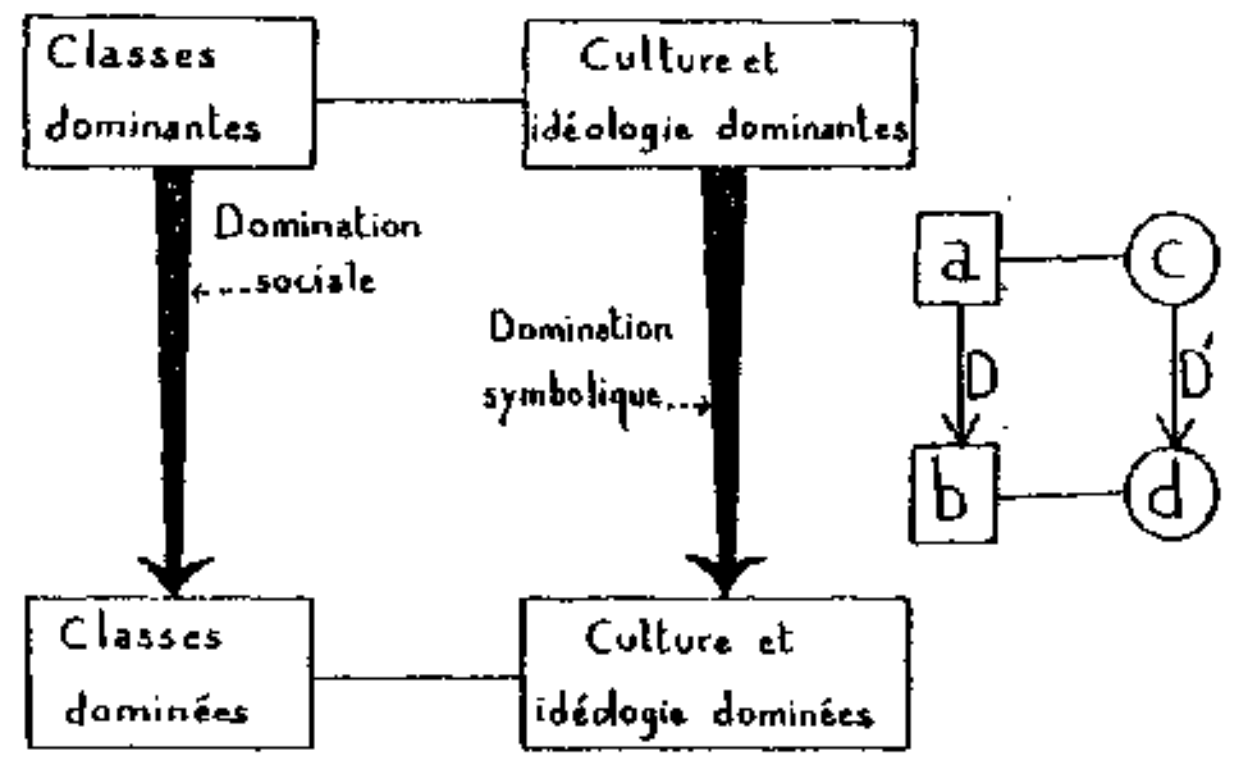

Les idées dominantes, a-t-on tendance à lire, sont aux idées dominées comme les classes dominantes sont aux classes dominées. Le schéma tient aussi sa force de se dérouler tout seul pour suppléer aux termes manquants :

$c: d:: a: b ; D^{\prime}$ est homologue de D

$a$ est à $b$ comme $c$ est à $d$, c'est-à-dire que la relation entre des idées de classes dominantes et des idées de classes dominées est du même type, produit ses effets dans la même logique, que le rapport social de domination d'une classe dominante sur une classe dominée. Le propre de ce schéma est, en rabattant la relation de domination symbolique sur une relation d'extériorité, de biffer par cette opération algébrique tous les phénomènes qui dans une relation symbolique sont au contraire de l'ordre de la composition, de l'inter-pénétration, de l'ambivalence, etc.

L'homologie entre domination sociale et domination symbolique, entre rapports de force et rapports de sens ne figure, il est vrai, qu'en creux dans le paragraphe marxien : il n'est jamais dit que les idées des classes dominées sont des idées dominées : idées et classes dominées ne sont même pas nommées. C'est pourtant ce schéma homologique qui s'est diffusé largement, du fait sans doute de sa commodité énonciative plus encore qu'à cause de sa signification théorique, interdisant ou dissuadant les analyses sociologiques portant 
sur la logique ou les particularités du rapport de domination symbolique - et pas seulement dans la tradition marxiste.

Ce qu'oublient le plus volontiers marxistes et non-marxistes est sans doute ce qui intéressait le plus Marx-sociologue : l'ensemble des relations explicatives entre les idées fortes et la condition ou la position de ceux qui les stabilisent et leur donnent un poids social comme «idées de leur domination » (ibid.), c'est-à-dire la fonction de légitimation qui opère le long du trait horizontal supérieur du schéma 1 . Témoigne de cette désociologisation du texte marxien (qui s'y prête, ne le cachons pas, par ses concepts ultimes) l'usage vertical du schéma marxiste "dominant-dominé », presque toujours coupé de l'argumentation à laquelle il servait dans le «Feuerbach ", à savoir la polémique toute naturelle chez un «historien matérialiste» (ce qui se traduirait aujourd'hui par historien-sociologue) contre l'hégélianisme cornue illusion « qui consiste à croire que la domination d'une classe est uniquement la domination de certaines idées ${ }^{2}$ » et plus généralement contre l'histoire philosophique « qui croit sur parole ce qu'une époque dit d'elle-même et les illusions qu'elle se fait sur soi ${ }^{3}$ ». C'est à Stirner qu'en avait Marx, à ses « trois efforts » pour établir la souveraineté de la hiérarchie des idées :

- séparation entre « les idées de ceux qui, pour des raisons empiriques, dominent ", et «ces hommes eux-mêmes »;

- établissement d'un « lien mystique entre les idées dominantes successives »;

- incarnation de l'histoire du Concept dans les intellectuels, les "penseurs", les " philosophes ", « qui sont considérés à leur tour comme les fabricants de l'histoire, comme les dominateurs ${ }^{4} »$.

16 Ceci ne serait aujourd'hui que de bonne ou triviale sociologie. L'impasse proprement marxiste dans laquelle ces analyses engagent la sociologie est ailleurs. Nous y reviendrons.

Bref, la connaissance des rapports de force entre groupes et classes n'apporte pas sur un plateau la clé de leurs rapports symboliques et du contenu de leurs cultures ou de leurs idéologies. Je me permets d'y insister parce que je vois souvent opposer une lecture minimalement marxiste de $L a$ reproduction ${ }^{5}$ à la tâche de décrire les mécanismes complexes de la domination symbolique ou les relations qui n'unissent qu'indirectement le fonctionnement des cultures dominantes et dominées à la domination sociale. C'est à croire que la lecture caricaturalement marxiste que firent en coup de vent de cet ouvrage J.-F. Revel (dans L'Express) et R. Peyrefitte (dans France-Soir) fut pour beaucoup la bonne : les rapports de sens redoublent les rapports de force, point final.

"L'effet proprement symbolique» de tout pouvoir social d'imposition du sens est effectivement défini, dans le paradigme conceptuel de La reproduction (propositions 0 , 1.1, 1.2, 2), comme l'ensemble des effets produits par la reconnaissance de sa légitimité que ce pouvoir est capable d'imposer en imposant la méconnaissance des rapports de force qui lui permettent d'exercer son action. Mais le « redoublement » des rapports de force que la force propre d'un symbolisme assure par la dissimulation des rapports de force qu'il est capable d'imposer (après tout cet axiome anthropologique n'est jamais que de Pascal) ne préjuge nullement des opérations culturelles et des opérateurs sociaux, toujours à décrire et jamais équivalents par lesquels s'opère cette constante transmutation sociale, celle des " châ̂nes de nécessité » en "chaînes d'imagination » (si, là encore, on préfère parler comme Pascal pour nommer en son principe la "grimace» sociale). De même, l'« arbitraire culturel » de tout symbolisme, dominant ou dominé, n'apparait comme tel - faut-il le rappeler? - que dans la comparaison avec d'autres qui, en révélant 
l'impossibilité de déduire les « choix » d'une culture de quelque principe universel que ce soit (logique ou biologique), fait comprendre que sa reproduction impose un «travail pédagogique » pour imposer ce qui ne va jamais de soi, dans la socialisation, l'éducation ou la légitimation. Mais les choix d'un symbolisme révèlent toujours une nécessité quand on les rapporte, par l'analyse historique ou sociologique, à la condition et à la position sociales de ses pratiquants et de ses reproducteurs - faute de quoi l'histoire et la sociologie de la culture n'auraient même jamais eu lieu de balbutier. L'arbitraire culturel n'est pas du même ordre que l'arbitraire linguistique: il ne suffit pas de le poser en principe (ce que fait le populisme) pour ouvrir un champ de description et de connaissance empiriques. Autrement dit, le schéma qu'on pourrait tirer de la reproduction pour localiser les tâches de description et d'explication qui incombent à la sociologie de la culture, est quelque peu différent du schéma de la vulgate marxiste que nous examinions à l'instant :

Schéma 2

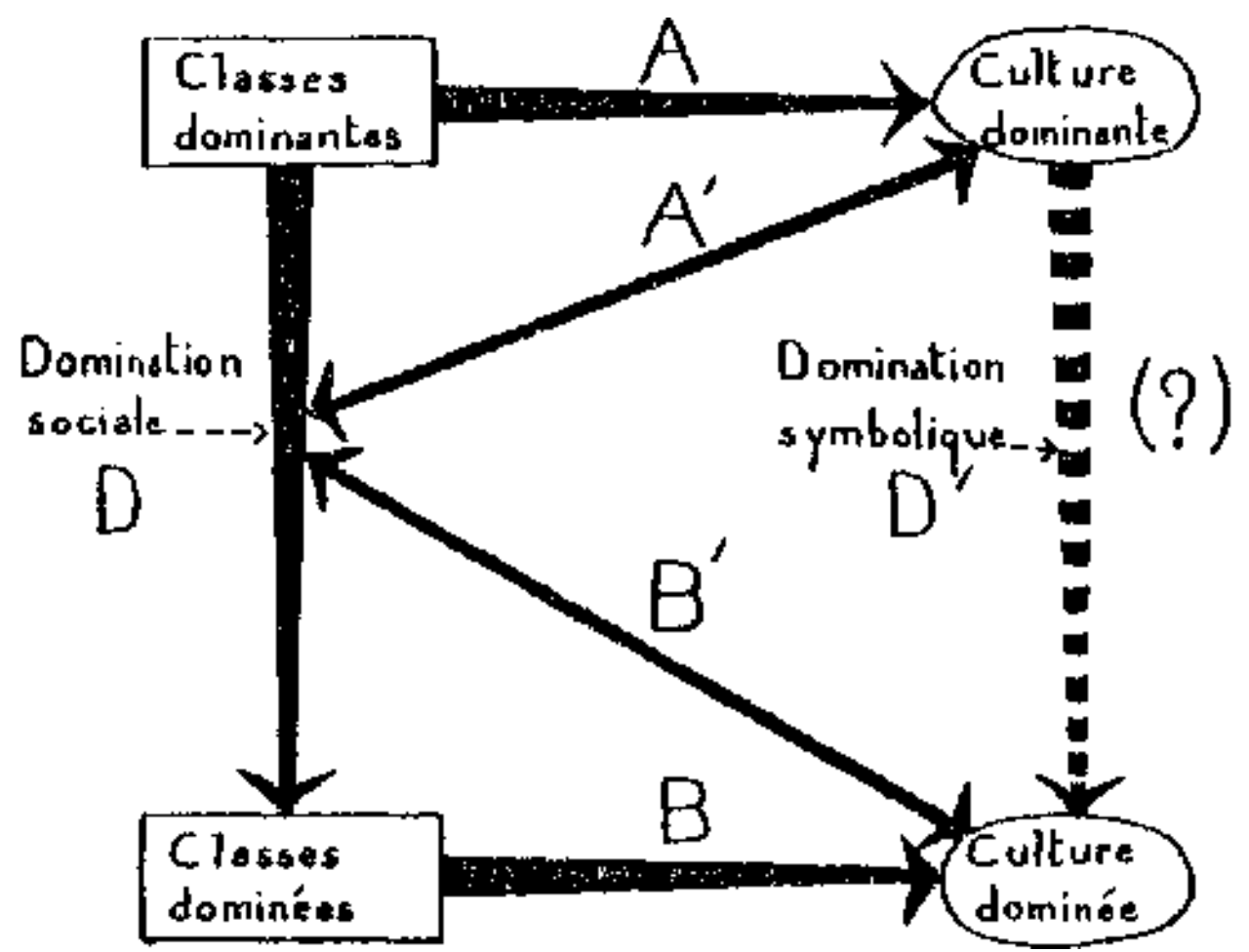

Qu'est-ce à dire ? D'abord et surtout que, loin de détenir d'avance la réponse, quand on se demande, dans une configuration donnée, ce qu'est le rapport de domination symbolique entre une classe dominante et une classe dominée, il faudrait que la description ait parcouru aussi complètement que possible les relations A, A', B, B' (avec ce que cela suppose de la connaissance sociologique de D) pour donner un contenu à D'. On ne peut transposer la connaissance de D en D' : on n'a pas ici une flèche homologique mais un point d'interrogation. Une sociologie de la culture qui veut intégrer à ses analyses les faits de domination a toujours affaire à un circuit complexe d'interactions symboliques et de constitutions de symbolismes. Les descriptions de type A ou B qui mettent en relation une culture de classe avec la condition sociale de ceux qui la pratiquent (analyse culturelle) rencontrent nécessairement des propriétés qui sont aussi des propriétés de position et qui font intervenir D. Si l'on se refuse à laisser échapper le sens que des pratiques 
symboliques doivent non seulement à la position sociale de leurs pratiquants mais encore aux fonctions qu'elles assument par rapport à la domination sociale (analyse idéologique), il faut décrire les effets symboliques que les relations de type A' et B' déterminent dans le fonctionnement d'une culture dominante et d'une culture dominée. Se référant à $\mathrm{D}$, les intériorisations de la dissymétrie sociale sont évidemment dissymétriques elles-mêmes ; qui voit la culture légitime du point de vue d'une culture dominée ne voit pas la même culture que celui dont elle légitime la position, mais B' peut aussi devoir à B des rapports différents à la légitimité culturelle : la reconnaissance d'une légitimité qui rend illégitime les pratiques de ceux qui la reconnaissent peut prendre en fonction des caractéristiques de la condition sociale toutes sortes de valeurs, de l'intériorisation pure et simple de sa propre indignité culturelle à la dénégation en passant par les accommodements ou les acceptations à éclipses. De même A' peut devoir à $\mathrm{A}$ des rapports différents à l'illégitimité des cultures dominées depuis le mépris qui dénie tout bonnement l'existence culturelle des dominés jusqu'à la complaisance populiste en passant par tous les degrés de la reconnaissance sous conditions ou du paternalisme. Ce sont toutes ces relations et bien d'autres qui composent en D' un système de relations dont l'effet proprement symbolique doit à l'oubli des cheminements qui mènent de D' à D - mais si indirectement - d'ajouter à $\mathrm{D}$ ce qu'un rapport de force ne produit jamais directement : un système de valeurs et de rapports aux valeurs qui est lui-même hiérarchique et hiérarchisant, sans pour autant se réduire à un pur décalque de la hiérarchie sociale.

Le schéma suggère évidemment l'apparence trompeuse d'un réseau routier que le chercheur pourrait parcourir sans problèmes. Ce n'est là qu'optimisme graphique. Nous avons vu que le pari théorique du relativisme culturel et celui de la légitimité culturelle, c'est-à-dire la description qui autonomise les cultures dominantes ou dominées de ce qu'elles doivent directement au rapport de domination pour se centrer sur leur cohérence culturelle (relations de type $\mathrm{A}$ ou $\mathrm{B}$ ) et la description qui interprète leur structure en rapportant leurs fonctions au rapport de domination (relations de type A' ou B'), n'additionnent ni ne composent aussi facilement leurs acquis de description. Nous verrons par exemple que A et A' ne partagent pas une culture dominée en deux-sousensembles de traits les uns « culturels », les autres « idéologiques » et qu'au contraire le même trait prend un sens différent dans les systèmes d'interprétation définis par les relations de type $A$ et de type A'.

21 Récapitulons rapidement, pour ouvrir la discussion, les principes, idéologiques ou théoriques, qui guident ou ont guidé le regard porté sur les classes dominées car nous aurons, je crois, souvent affaire à leurs oppositions et plus d'une fois à leurs complicités souterraines.

-1. Au début trône ou rayonne l'ethnocentrisme de classe naïvement porté par l'idéologie et la culture des classes dominantes et qui a peut-être eu quelque chose d'encore plus forcené, en tout cas de plus construit, dans leurs fractions intellectuelles. Ni le hobereau, ni le grand seigneur par exemple n'ont parlé avec autant de véhémence que Balzac de l'extra ou de l'infra-humanité de la paysannerie. Le regard porté par les classes dominantes sur les classes qu'elles dominent ne le cède en rien, par sa certitude dans le déni do culture, c'est-à-dire d'humanité, tel que le décrit Lévi-Strauss dans Race et histoire, au regard qu'une société porte spontanément sur une autre. On sait que l'ethnocentrisme a pu devenir exorbitant de tout contrôle rationnel lorsque l'histoire lui a ménagé quelque droit de conquête ou quelque fonction dans la désignation du bouc émissaire (racisme). Mais l'Europe du XIX ${ }^{e}$ siècle, à l'heure de son expansion mondiale, n'a jamais dit ou pensé 
sur les cultures colonisées ou satellisées pire, ou mieux, que ce qu'une bourgeoisie par exemple a pu dire de ses « classes dangereuses » ou de son « simple et bon peuple ». Dans nos sociétés de classe - entendons même celles où le rapport de classe est le plus pacifié et le plus euphémisme - le racisme de classe entendu comme certitude propre à une classe de monopoliser la définition culturelle de l'être humain c'est-à-dire des êtres qui méritent d'être pleinement reconnus comme tels, habite encore de vastes secteurs des classes dominantes, et pas forcément les plus «traditionnels » dès lors qu'on passe outre aux proclamations ou aux déclamations politiques pour enregistrer le discours silencieux des gestes, des petites décisions quotidiennes (sociabilité), pour ne rien dire des grandes (mariage). En tout cas lorsque licence lui en est donnée par l'inattention, la complicité de l'interlocuteur ou l'enjeu symbolique, le discours ethnocentrique de classe retrouve vite ses formulations les plus abruptes: celles qui renvoient les classes populaires à la «barbarie ", à la «nature ", à l'« inculture ": «ce sont des hommes" (cela permet de citer La Bruyère) mais quand même un peu moins que nous ne le sommes. La parlure populaire est entendue spontanément comme un "patois " social, miettes de langages ramassées à l'écoute maladroite, distraite ou perverse du vrai langage; les mœurs populaires fournissent l'expérience première et le paradigme primitif de la "vulgarité ", c'est-à-dire de l'absence de mœurs, ou, au mieux de mœurs qui ne seraient qu'une dérisoire ou patibulaire imitation des «bonnes » - pathétique ou amusante les jours où le cœur est à la générosité. Il suffit d'écouter de bonnes bourgeoises - ce qui aujourd'hui veut dire diplômées de l'enseignement supérieur - parler de leurs femmes de ménage ou, comme le dit Hoggart, une maitresse de maison des middle-classes de son plombier, prototype de « ces gens-là ».

-2. C'est de la tâche, jamais complètement achevée, de réduire les illusions ethnocentriques que se réclame le relativisme culturel qui pose, à partir du constat que tout groupe social possède son symbolisme irréductible, ou, si l'on veut son arbitraire culturel, le principe que les cultures doivent être décrites et non hiérarchisées, ou plutôt qu'on ne peut plus les hiérarchiser dès lors qu'on les décrit complètement à partir de leurs propres codes et non plus d'un code étranger. Mais l'ethnologie qui engendre le «culturalisme» comme technologie professionnelle ayant proclamé et, bon an mal an, pratiqué depuis un siècle ${ }^{6}$ la déontologie du relativisme culturel, il devenait difficile de ne pas faire bénéficier de cette générosité théorique les cultures populaires: pourquoi auraient-elles été privées de ce crédit en humanité, c'est-à-dire en auto-suffisance culturelle, que le relativisme ethnologique ouvrait à toutes les cultures de 1'oikoumène? La réhabilitation des cultures populaires a donc suivi, mais avec retard, celle des cultures lointaines. Ce cultural lag dans l'application du relativisme culturel aux groupes que l'anthropologue avait sous le nez explique sans doute, dans la logique du rattrapage ou de l'exacerbation, qu'il ait toujours eu quelque chose de plus forcé qu'en ethnologie (folklorisme ou Proletkult), préférant presque toujours l'idéologie populiste de l'inversion des valeurs («ils valent mieux que nous», leur culture est tellement plus culturelle, tellement plus « naturellement culturelle » que la nôtre) à la patience de l'observation qui aurait montré qu'en décrivant toutes les relations dans lesquelles fonctionne une culture populaire on découvre nécessairement dépendance et hétéronomie. C'est, aussi, que le relativisme culturel appliqué à la connaissance des cultures populaires n'apparaît dans les sciences sociales que bien après le même mouvement de conversion dans l'idéologie politique des intellectuels : le populisme politique, avant le prolétarisme, avait eu tout le temps de miner idéologiquement le terrain et les concepts de la recherche: aux tentatives d'utilisation directement politiques par les intellectuels (que ce soit sous la 
forme cynique de l'hébertisme du Père Duchêne ou sous la forme millénariste du babouvisme et des carbonarismes) avait succédé une longue histoire de la manipulation du Peuple par concepts interposés qui l'impliquaient dans des affrontements et des enjeux entre fractions intellectuelles, avant que le compagnonnage de route consenti par les intellectuels à des organisations ouvriéristes ne complique encore les choses. Bref, dans le registre politique le populisme a précédé l'antiracisme; il s'est même quelque temps accompagné de racisme (« les plus humbles de chez nous valent encore mieux que les meilleurs des autres »), alors que dans les sciences sociales ce serait plutôt l'inverse. Mauvaise configuration pour que le relativisme culturel appliqué aux cultures populaires relativise ses principes et prenne au sérieux les effets sociaux et symboliques du rapport de domination, puisqu'ici il s'encourageait surtout de le dénier ou de jouer à son inversion.

-3. Si l'on veut relativiser les descriptions que procure le relativisme culturel lorsqu'il applique sans autres précautions son principe d'autonomisation aux cultures populaires en refusant de les décrire par référence à la culture des classes dominantes, il faut passer à un autre type de description, celui qu'explicite nettement la théorie de la légitimité culturelle. Par son principe constitutif - restituer le sens des différences culturelles au système des différences de force entre les groupes d'une même société - celle-ci prend en compte le rapport de domination, c'est-à-dire le système complexe de mécanismes et d'effets de hiérarchisation qui, dans une société de classes, constitue une réalité sociale dont nul ne peut faire l'hypothèse qu'elle serait, par miracle, dépourvue de tout effet culturel (hypothèse implicite d'une description intégralement relativiste). Ce rappel au réalisme sociologique rattache assurément la théorie de la légitimité culturelle à un principe bien reconnaissable de la théorie marxiste (ce qui explique la facilité que se donnent certains lecteurs ou utilisateurs de l'y réduire), mais elle prolonge aussi un choix théorique de la sociologie wébérienne, celui de restituer à une description complète des rapports de force, la force symbolique que constitue la reconnaissance d'un "ordre " comme «ordre légitime» par l'ensemble des groupes sociaux que cet ordre distribue pourtant inégalement en termes de commandement et d'obéissance, de "chances positives » et de «chances négatives ». Autrement dit cette théorie puise ses hypothèses dans la transposition à l'ordre culturel des concepts que Weber utilisait pour décrire les effets d'ordres comme ceux de la légitimité religieuse, politique ou juridique ainsi que pour classer en "types» (charismatique, traditionnel, rationnel) ces différents ordres légitimes. L'analyse des cultures de classe doit à Marx et à Weber une double raison de se refuser à l'emploi machinal du relativisme culturel: le sociologue ne peut escamoter, dans la description des différentes cultures de groupes ou de classes, les rapports sociaux qui les lient dans l'inégalité de force et la hiérarchie des positions, puisque les effets de ces rapports sont inscrits dans la signification même de l'objet à décrire. En ce sens, dire d'une culture qu'elle est « légitime » est bien évidemment une assertion axiologiquement neutre (même si on voit parfois cette "neutralité » se perdre en chemin, selon l'humeur des utilisateurs), mais c'est une assertion doublement contraignante: ce n'est pas seulement s'obliger à montrer que la culture légitime est celle des dominants, c'est aussi s'astreindre à démontrer (ce qui n'en découlerait mécaniquement que dans le schéma marxiste) qu'elle est une culture dominante, i. e. qu'on peut identifier empiriquement chez ceux qu'elle exclut des comportements de reconnaissance des valeurs qui les excluent (culture savante, scolarisation, mœurs, etc.). La théorie de l'ordre culturel légitime assigne clairement un terrain au travail empirique, celui d'une sociologie des formes et des degrés du consentement. 
25 Ainsi formulé, le principe descriptif de la théorie de la légitimité culturelle laisse voir que celle-ci ne saurait fournir une clé universelle pour la sociologie des cultures populaires ni constituer le "savoir absolu», le "point omega » de toute sociologie de la culture. Elle possède, comme le relativisme culturel, mais de manière inversée, sa force et ses limitations, qui varient elles-mêmes en sens inverse selon l'objet de la description: cultures populaires ou cultures dominantes. Sa force, c'est évidemment de ne pas subordonner abstraitement toute description des cultures de groupes ou de classes à un relativisme culturel que ces groupes ne pratiquent pas eux-mêmes - dont ils composent leur culture de ne pas le pratiquer - c'est donc de restituer - forme plénière de la démarche sociologique que trahit le culturalisme classique - le sens culturel des pratiques aux conditions et aux positions sociales entre lesquelles ce sens se débat, se négocie et se conclut, bref, de toujours nommer ce que l'anthropologie décrit et interprète, par référence aux instruments sociaux de description et d'interprétation qui «ont cours » dans la société dont elle entend être la sociologie. La limite de la théorie de la légitimité, c'est qu'elle ne peut, dans le moment même où elle objective l'arbitraire de la culture des classes dominantes, en décrivant les rapports de force qui fondent la légitimité des cultures dominantes dans l'oubli des rapports de force que ceux-ci sont capables d'imposer, décrire positivement l'arbitraire des cultures dominées, i.e. décrire dans toutes ses dimensions symboliques ce qui est et fonctionne encore comme culture même quand il s'agit de cultures dominées. Un pas de plus dans la revendication du monopole descriptif, et la théorie de la légitimité culturelle bascule à son tour dans le déni de description : les pratiques et les traits culturels des classes populaires se trouvent privés du sens qu'ils tiennent de leur appartenance à un système symbolique propre lorsque le sociologue énonce comme exclusif le sens qu'ils tiennent de leur référence à un ordre culturel légitime (infraction, erreur, maladresse, privation de codes, distance, conscience honteuse ou malheureuse de cette distance ou de ces manques). De même que les cécités sociologiques du relativisme culturel appliqué aux cultures populaires encouragent le populisme, pour qui le sens des pratiques populaires s'accomplit intégralement dans le bonheur monadique de l'autosuffisance symbolique, de même la théorie de la légitimité culturelle risque toujours, par sa systématicité énonciative, de conduire au légitimiste qui, en sa forme extrême du misérabilisme n'a plus qu'à décompter d'un air navré toutes les différences comme autant de manques, toutes les altérités comme autant de moindre-être - que ce soit sur le ton de l'élitisme ou sur celui du paternalisme.

-4. Il suffit de parcourir les travaux des anthropologues et des sociologues des classes populaires pour apercevoir, toujours récurrente, la même difficulté théorique : chacun des deux types de description (2 et 3) réussit surtout à faire voir ce que l'autre manque du sens des pratiques populaires. Il semble qu'on ne puisse faire les deux choses en même temps, sinon par la précaution verbale qui est accessible à tous, du moins dans le travail de construction des faits et des énoncés interprétatifs. On ne peut, par exemple, appréhender les valeurs de la vie populaire comme faits culturels dotés de tous les aspects d'un symbolisme, sans remettre en cause les énoncés descriptifs qui imposent la légitimité culturelle comme étalon de toute valeur; de même qu'on ne peut entreprendre d'analyser le fonctionnement d'une machinerie symbolique comme celle d'un ordre culturel légitime sans, par cette analyse même, dissoudre en non-valeurs les valeurs populaires. Mais on ne peut non plus accompagner jusqu'au bout la cohérence expressive d'une culture populaire sans lui faire au bout du compte l'injustice interprétative 
d'escamoter l'hétéronomie symbolique qui lui marque sociologiquement un tout autre sens, tout aussi total.

« Diable !» dira-t-on : « Il y aurait donc sur les cultures populaires des recherches et des chercheurs, les uns relativistes (voire populistes), les autres légitimistes (voire misérabilistes) ? Nommez-les donc, qu'on s'y retrouve un peu.» Patience, la frontière dont, nous parlons court sinueusement en toute description des cultures populaires qu'elle partage presque toujours en mouvements alternatifs d'interprétation, en balancements successifs, en phraséologies de la double détente, et parfois de la double entente. L'oscillation entre les deux manières de décrire une culture populaire s'observe dans la même œuvre, chez le même auteur, parce qu'elle habite toute sociologie, voire toute description romanesque un peu fouillée des choses de la vie populaire. Il y a, bien sûr, des intégristes du dogme populiste ou du dogme misérabiliste, des systématisateurs de la vie dévote de l'intellectuel et du salut culturel des niasses : moines-entomologistes consacrant leurs veilles émerveillées au répertoire des "richesses" de la culture populaire, entêtés à fermer leurs oreilles à tout bruit tentateur venu du monde de la domination symbolique; ou prédicateurs impitoyables d'une politique des «vraies valeurs » de la vie culturelle, fustigeant, comme le péché du monde par leurs chiffres de non-fréquentation des musées, des concerts, des théâtres ou des bibliothèques, les païens non encore convertis aux délices spirituelles de la culture légitime. Mais chez les sociologues - mesure professionnelle oblige - l'oscillation semble bien être le cas modal: tout mouvement un peu trop vif dans un sens appelle un mouvement de repentir qui se lit dans la légère exagération du recours à la théorie inverse (légitimiste ou relativiste) que la phrase descriptive s'impose comme une petite expiation énonciative de ses excès de cohérence.

Nous arrivons donc, in fine, à la question dont il nous faudra repartir: l'oscillation théorique entre les deux styles de description (2 et 3 ) est-elle une démarche indépassable pour le sociologue? On peut douter qu'elle soit une stratégie efficace du travail d'interprétation quand on aperçoit qu'elle se réduit à corriger chaque embardée par une autre de sens inverse: les coups de godille successifs - un coup à droite, un coup à gauche - n'ont jamais fait une «ligne ». La sociologie des cultures populaires ne sauraitelle concevoir une théorie spécifique de la description de son objet? ou au moins une théorie de l'articulation consciente des deux styles de description?

C. GRIGNON.- J'aimerais exemplifier ce qui vient d'être dit en partant du travail que je mène actuellement sur l'alimentation populaire et en faisant à mon tour l'exercice de construction d'objet que je demande aux participants habituels de l'Atelier. Disons d'abord qu'on ne peut espérer faire un usage contrôlé de la notion île culture populaire que si l'on définit celle-ci par la relation qui l'unit aux classes dominées, c'est-à-dire comme la culture des classes populaires, et non comme la culture du «Peuple». Cette préférence de principe accordée au critère sociologique sur les critères culturologiques, comité le caractère oral ou l'anonymat de la tradition, plus familiers aux ethnologues et aux spécialistes du folklore, ne doit pas nous empêcher de prendre également au sérieux les tâches auxquelles oblige le terme de culture: le meilleur moyen est sans doute d'entreprendre l'inventaire des « traits » qui constituent une culture populaire ${ }^{7}$. Essayons donc, pour commencer, de voir comment, selon quels principes, on pourrait situer les 
pratiques alimentaires par rapport à d'autres ensembles de pratiques dont on sait ou dont on peut raisonnablement présumer qu'ils font, eux aussi, partie de la culture des classes dominées.

Dans la mesure où la fréquence des réceptions et des invitations décroît à mesure qu'on descend dans la hiérarchie sociale, on peut dire que l'alimentation populaire appartient à la sphère de la vie familiale et privée ; en tant qu'activité productrice, elle se situe vers le pôle féminin de la culture populaire, du côté de la culture domestique par opposition à la culture de métier. Pratique familiale, l'alimentation fait partie de la culture établie, plus ou moins intégratrice, des ménages par opposition aux formes populaires de la culture adolescente, marginale, contestatrice et déviante ; pratique domestique, elle s'oppose aussi bien à la culture de la rue qu'à la culture de l'atelier; pratique privée, elle fait partie de ce secteur protégé de la culture populaire qui échappe, au moins matériellement, à l'action directe des mécanismes de domination symbolique. Dans un schéma construit selon ce principe, les pratiques alimentaires se situeraient, avec l'ensemble des tâches ménagères, à l'opposite des pratiques relevant de la culture politique des classes populaires - participation à des grèves, à des manifestations, etc. Notons cependant que l'alimentation populaire ne se laisse pas complètement et automatiquement ranger, comme c'est le cas de l'alimentation petite-bourgeoise, du côté de l'économie domestique et de la consommation pure ; en tant que " consommation réparatrice ", elle regarde vers l'extérieur, du côté du travail et des valeurs masculines; quel que soit le degré de "démanualisation", au demeurant inégal, du travail paysan et ouvrier, les goûts populaires reflètent encore, pour une part, la symbolique du corps attachée au travail de force et aux métiers «manuels ». On ne voit pas très bien où placer des traits pourtant distinctifs de l'alimentation populaire, comme, la culture de bistrot ouvrière - véritable négation de l'alimentation familiale - ou l'autoconsommation paysanne - expression de l'indivision entre le métier et la famille. Que faire si l'on entre plus avant dans le détail, de la " gamelle ", perpétuel objet de querelles domestiques, intermédiaire malheureux entre le chantier et la maison? Dans la mesure où la séparation entre la vie professionnelle et la vie privée est un des privilèges de la vie bourgeoise, que les classes populaires sont encore de train de conquérir, il nous faut rectifier notre schéma et décaler les pratiques alimentaires vers le centre, c'est-à-dire vers le point de rencontre entre la culture domestique et la culture de métier.

On pourrait aussi partir de l'opposition entre, d'une part, les éléments de la culture populaire qu'on peut considérer comme "indigènes ", dans la mesure où ils s'appuient sur des «traditions de classe » et où ils renvoient au fonctionnement interne de groupes relativement fermés, comme la famille ou le village, et, d'autre part, les consommations et les goûts d'importation récemment mis à la portée des classes populaires par le développement de la production et de la distribution de masse. Du côté des traditions populaires, on trouve évidemment l'héritage de la culture paysanne et des cultures régionales, qui se marque, en ce qui concerne l'alimentation, dans la persistance de plats traditionnels (comme la soupe), dans l'opposition entre les menus de la semaine et ceux du dimanche, dans l'horaire strict des repas, dans le recours à l'autoconsommation et à l'approvisionnement direct, etc. À cet héritage se rattachent, d'une manière plus générale, non seulement des traits de culture «folkloriques »-accents, survivances des parlers et des coutumes locales - mais des habitudes bien vivantes qui se manifestent au niveau des choix délibérés (par exemple dans la préférence accordée au logement individuel sur l'appartement), comme dans les routines inconscientes qui rythment la vie 
quotidienne (horaires de lever et de coucher, rythme des repas, etc.) ou encore dans le " conservatisme" de certaines représentations (par exemple en ce qui concerne les relations entre les sexes et entre les âges). À cet ensemble de traditions, sans doute plus vivaces dans ce qui reste de la petite paysannerie et chez les ouvriers d'origine paysanne que chez les ouvriers d'origine ouvrière, il faudrait ajouter l'héritage des cultures de métier d'origine artisanale, et, n'en déplaise à Van Gennep, l'ensemble des traditions ouvrières, du « folklore » de l'atelier à la culture syndicale ou politique. Du côté des goûts d'importation, on trouverait en premier lieu tout ce qui a trait à la diffusion de l'automobile, de la télévision (et, auprès des jeunes, de la radio et du disque), au développement des loisirs, et aussi, d'une manière moins spectaculaire, à la propriété et à l'équipement du logement; pour l'alimentation, la fréquentation des supermarchés, l'usage de conserves et d'ersatz, la recherche de produits à la fois pratiques et bon marché, l'apparition de goûts et de "besoins » nouveaux, etc. Entre ces deux pôles se situeraient des pratiques "rituelles», "typiquement populaires», mais dépendant néanmoins d'institutions extérieures, comme l'assistance a des matchs, le tiercé (ou son pendant, le livret de caisse d'épargne) etc.

Dans la mesure où elles se situent au point de rencontre entre les bouleversements rapides de la technique et de l'économie et le «temps long» des habitudes enracinées dans les cultures (nationales, régionales ou de classe), les pratiques alimentaires sont un objet privilégié pour étudier les transformations de ce goût à la fois invétéré et précaire qu'est le goût populaire; elles invitent a analyser la dépendance de celui-ci non plus seulement par rapport à la dimension symbolique de la culture dominante, mais aussi par rapport à ses aspects matériels. Il reste qu'on s'expose, en se plaçant sur ce terrain, à réintroduire, par le biais de l'opposition construite entre traits indigènes et traits exogènes, l'opposition naïve entre l'« authentique » et l'« artificiel » qui hante aussi bien les restaurations animées par l'«esprit d'antiquaire» que les reconstitutions simplificatrices de tendances qui mettent directement en rapport la liquidation supposée du goût populaire et le développement du « capitalisme ». Le sociologue n'a évidemment plus grand-chose à dire de la culture populaire contemporaine dès lors qu'il la considère soit comme une survivance, soit comme le reflet pur et simple de la "production", et qu'il fait donner des "concepts bulldozers», comme "urbanisation», "industrialisation", "culture de masse", "société de consommation", etc., qui déblaient si bien le terrain qu'on ne distingue plus rien après leur passage. Il faut, à l'inverse, se donner les moyens empiriques d'étudier la relation entre les consommations et les goûts, essayer de reconstituer la logique, différente selon les groupes et selon les époques, des emprunts et des re-traductions, examiner dans quelle mesure les différentes couches des classes populaires parviennent à s'approprier, matériellement, mais aussi symboliquement, les biens de grande consommation, etc.

On pourrait encore distinguer, connue l'ont fait les folkloristes anglais, entre les aspects matériels de la culture populaire (objet de l'ethnographie) et les aspects symboliques (objet $\mathrm{du}$ folklore proprement dit). Cette fois, sur notre schéma imaginaire, les pratiques alimentaires se trouveraient rangées du côté de la consommation des biens matériels, comme le logement, l'équipement ménager ou l'automobile ; à l'autre bout, on trouverait les pratiques correspondant à la consommation des biens culturels destinés au "grand public » ou, explicitement, au public populaire : littérature, journaux (« presse du cœur », presse spécialisée dans les faits divers ou les pronostics hippiques), radio (en fond sonore sur l'autoradio ou sur le transistor du chantier, de l'atelier ou de la cuisine), émissions de 
télévision (variétés, sports), chansons, etc.; entre les deux, on trouverait les pratiques culturelles liées aux loisirs, comme le camping, la fréquentation des bals, des fêtes foraines, l'assistance aux matchs de football, etc. Toujours selon ce principe, on pourrait ranger les pratiques alimentaires du côté des aspects « manuels » de la culture populaire, la cuisine, la vaisselle ou la préparation des conserves familiales allant de pair avec le ménage ou le bricolage intensif et s'opposant à l'ensemble des activités intellectuelles, et, en premier lieu, à tout ce qui a trait au langage (on voit que sous ce rapport ma voie d'accès à la culture populaire est diamétralement opposée à celle d'un sociolinguiste). Un pas de plus, et on pourrait classer les pratiques alimentaires parmi les activités utilitaires et obligatoires avec le jardinage, la couture ou le tricot ; 4 l'autre extrémité du schéma, on trouverait les jeux et les sports, belote, pétanque, flipper, fléchettes, tiercé, football, etc. On voit que ce schème, appliqué au cas-limite de l'alimentation rappelle fortement l'opposition entre la base matérielle (ici biologique) de la vie sociale et les variations - les «broderies »- exécutées par la Culture, ou encore l'opposition entre le " nécessaire » et le « gratuit » ou le « désintéressé ».

De fait, l'opposition entre les aspects pratiques et les aspects stylistiques de la culture populaire ne se voit sans doute jamais autant que dans les techniques du corps, avec, « en bas ", l'alimentation, comme technique élémentaire de l'entretien biologique, et, « en haut ", tout ce qui constitue le corps comme symbole et comme moyen d'expression, parure, posture, gestes, mimiques, etc. Mais remarquons à ce propos que les classes dominantes n'ont pas le monopole de la stylisation de la vie. Que la culture populaire s'objective rarement - exception faite des cultures paysannes «traditionnelles »- dans des produits durables, et plus rarement encore dans des "œuvres", ne doit pas faire oublier qu'elle peut elle aussi se donner pour fin explicite la production de formes et de signes. Sans parler du langage - auquel il est quand même bien difficile de refuser l'intention stylistique - la stylisation populaire de la vie se voit à l'évidence dans la culture adolescente (décoration d'objets techniques « fétiches", comme les autos ou les motos, maniérisme pointilleux du costume et de la cosmétique), dans la «culture de bistrot ", dans la " culture de la rue », et, d'une manière générale, dans tout ce qui a trait à la « mise en scène de la vie quotidienne » et à la " présentation de soi »- à la «frime », pour prendre un vieux mot populaire récemment remis a la mode.

Sans entrer immédiatement dans une discussion de fond, notons dès maintenant quelques-unes des questions que soulève, me semble-t-il, l'application à la culture populaire et à la relation que celle-ci entretient avec la culture dominante, de l'opposition entre le « matériel » et le «symbolique ». Peut-on réduire la «culture matérielle » à ses aspects "utilitaires»? Une pratique, un bien sont-ils d'autant moins "symboliques " qu'ils sont plus utiles ou plus " nécessaires »? Ira-t-on jusqu'à prétendre que les outils nécessaires au travail de la "matière " ne sont pas, au mène titre que les biens de consommation symboliques, l'objet d'une compétence et d'un goût, le support d'un ensemble de valeurs et de représentations collectives? N'est-ce pas toujours, en fin de compte, par référence à la hiérarchie dominante des pratiques et des consommations culturelles qu'on peut dire qu'il y a des pratiques «moins symboliques » que d'autres - et, "à la limite", des pratiques "pas symboliques du tout»- et que ces pratiques constituent une part de plus en plus importante de la «culture » à mesure qu'on descend dans la hiérarchie sociale? Sans parler de la définition particulière du Beau (par opposition à l'Utile) et des choix esthétiques inconscients et ultimes auxquels renvoie très probablement l'opposition entre « goûts de liberté » et « goûts - ou plutôt non-goûts - de 
nécessité », n'est-ce pas se laisser piéger par l'application mécanique d'une métaphore mécanique que de penser que le «jeu» diminue quand l'«étau» des contraintes se resserre? En admettant que les classes populaires ne puissent se livrer autant que les classes moyennes ou dominantes à la «stylisation de la vie ", peut-on dire pour autant que leur style de vie est un style de vie " en soi ", c'est-à-dire, au bout du compte, un style de vie sans style? Ne dit-on pas, tout autant, que la stylisation, toujours plus ou moins voulue, plus ou moins forcée, est le contraire du «vrai » style? N'est-ce pas du valet, et non du maitre, qu'on dit qu'il est « stylé » ? La sociologie du goût doit-elle donc faire deux poids deux mesures, et se donner des définitions différentes du style - et du « naturel »selon qu'elle oppose le mode de vie des classes populaires à celui des classes moyennes, ou, à l'autre bout de l'échelle sociale, le mode de vie des fractions intellectuelles ou de la "nouvelle bourgeoisie» à celui des fractions anciennes et établies des classes dominantes, patronat «de vieille roche », aristocratie ? Du reste, est-il si certain que la part de la culture orientée vers la stylisation de la vie décroisse quand la vie devient plus dure, plus "serrée » et plus " sérieuse ", et qu'elle disparaisse tout à fait, au niveau des classes populaires, quand on passe de l'adolescence à l'âge mûr, du célibat au mariage, du loisir au travail ? Ne serait-ce pas plutôt que la stylisation de la vie prend ici d'autres formes, moins visibles et moins aisément déchiffrables pour un observateur appartenant aux classes dominantes?

Nous aurons certainement l'occasion de revenir sur ces questions. Contentons nous pour l'instant de préciser notre vocabulaire, de parler de culture pratique plutôt que des aspects « utilitaires » ou " intéressés » de la culture populaire; au lieu de raisonner d'emblée en termes de " nécessité » et de « liberté », définissons provisoirement la culture pratique, par opposition à la consommation de biens culturels et aux techniques visant ou concourant à la stylisation de la vie populaire, comme l'ensemble des pratiques entretenant un rapport direct avec les conditions matérielles d'existence, avec les conditions de vie et le niveau de vie.

37 Continuons l'exercice. Il me semble, rétrospectivement, que j'ai dû conquérir mon objet contre deux séries différentes d'obstacles. Du côté de la rupture avec les prénotions, le projet d'apporter une explication sociologique aux variations du comportement alimentaire rencontre plusieurs objections, pas si faciles à écarter dans la mesure où le sens commun s'appuie sur une sociologie spontanée renforcée par l'idéologie dominante et par l'égocentrisme des disciplines concurrentes. Les inégalités socio-économiques ne se sont-elles pas reportées, dès lors qu'on est entré dans la "société de consommation", vers des biens plus coûteux et plus rares, comme le logement, l'éducation ou les loisirs? L'industrialisation, l'urbanisation, n'entraînent-elles pas, là comme ailleurs, un nivellement des consommations, la disparition des comportements traditionnels, et l'émergence d'un mode de vie et d'un goût standard? Ne se trouve-t-on pas, en outre, dans un domaine où l'explication des comportements collectifs est à rechercher dans la biologie plutôt que dans la sociologie, comme en témoigne l'opposition entre goûts d'hiver et goûts d'été, ou entre l'alimentation des jeunes et celle des vieux? La clé des différences sociales qu'on peut encore repérer, par exemple entre l'alimentation des manuels et celle des non-manuels, n'est-elle pas dans les mécanismes physiologiques? Autre objection, géographisante : symbole «bon enfant » de "l'identité » nationale ou régionale, les habitudes alimentaires ne sont-elles pas ce qui unit les Français en les opposant aux Anglais ou aux Allemands, les buveurs de vin par opposition aux buveurs de bière ou de cidre? Au lieu de s'obstiner à vouloir les traiter comme des marqueurs 
sociaux, ne faut-il pas les considérer comme des traits de culture? Objection psychologisante, enfin : que fera le sociologue, confronté à la diversité des goûts (et des dégoûts) entre les membres d'une même famille? Admettons qu'il ait son mot à dire tant qu'on en reste au niveau des consommations ou des pratiques; mais les préférences et les aversions alimentaires proprement dites ne sont-elles pas avant tout affaire de psychologie individuelle, de psycho-physiologie, de psychanalyse?

En ce qui concerne la seconde série d'obstacles dont je parlais tout à l'heure, il faut rappeler le caractère idiographique et descriptif, très proche le plus souvent de l'enquête sociale, de la plupart des travaux consacrés par les sociologues à l'alimentation, et, plus généralement à la "vie quotidienne » des classes populaires; par ailleurs, j'avais pour ainsi dire sous la main les outils théoriques forgés par Pierre Bourdieu, dans le prolongement des travaux du Centre de sociologie européenne sur l'éducation et sur l'art, pour l'étude des goûts cultivés ${ }^{8}$. Tout m'incitait, dans ces conditions, à « construire mon objet » en sélectionnant les pratiques les plus "désintéressées ", les plus rares, les plus sélectives, les moins excentriques par rapport à la «sphère de la légitimité », et en laissant délibérément de côté les aspects les plus matériels, les plus utilitaires et les plus communs de l'alimentation; je n'avais qu'à centrer la recherche sur la gastronomie (i. e. sur «la consommation ostentatoire des biens de luxe») plutôt que sur l'alimentation domestique, ou encore sur la diffusion des normes dominantes en matière d'hygiène et d'esthétique corporelle.

Mais, si commode et si recommandée qu'elle soit, cette abstraction se paye d'une double exclusion: d'une part des aspects de la culture les plus directement liés aux contraintes économiques et matérielles; d'autre part de la culture « indigène » des classes populaires. Bien sûr cela ne m'apparaissait pas aussi nettement au début de mon travail ; mais il me semblait dommage, sur un sujet pareil, de réserver l'essentiel de l'analyse, et en tout cas le tout de l'analyse interne, à ce qui se passe "en haut " de la hiérarchie sociale, de consentir à ce que la description perde sa richesse et la démonstration sa force à mesure que l'on s'éloigne du sommet de la " pyramide » sociale, bref de prendre une fois de plus, et d'une manière exclusive, un point de vue liante par le point de vue de la classe et de la culture dominantes. Devait-on, partant du constat des handicaps et des sousconsommations dont les classes populaires sont victimes, y compris en ce domaine, se borner à transposer à la sociologie de la consommation les schèmes de la sociologie de l'éducation et de la culture savante, et se contenter d'interpréter les pratiques alimentaires des classes populaires en termes d'élimination, de relégation, de retard culturel, d'écart à la norme, d'erreur de déchiffrement? Fallait-il donc se résoudre, une fois encore, à faire comparaître la culture des classes dominées par défaut, et s'arrêter, comme d'habitude, devant le retranchement qui, depuis Halbwachs, passe entre les classes moyennes et les classes populaires et sépare ces dernières de la "société ", véritables limes inférieur sur lequel viennent buter les analyses de la sociologie de la culture?

Évacuer de la sorte les aspects pratiques des pratiques alimentaires, c'était contribuer à accroitre encore l'écart entre la pyramide des faits sociaux et la pyramide des faits sociologiques, du moins des faits reconnus et retenus par la sociologie des goûts cultivés. De l'alimentation ordinaire des gens ordinaires et plus généralement de la culture pratique, on peut dire à peu de choses près ce que Labov, voulant justifier ses choix de départ, dit du vernaculaire du prolétariat noir par opposition à ce qu'il appelle le «dialecte de la classe dominante», à savoir qu'il constitue «le courant principal de 
l'histoire linguistique » et qu'« il touche d'une façon bien plus intime un nombre bien plus grand de locuteurs». Je sais bien que le sociologue a beau jeu d'opposer son droit imprescriptible à l'abstraction savante à ce genre d'argument, toujours suspect de trop concéder aux attentes du sens commun et au demeurant pas complètement exempt de populisme. Mais, en construisant mon objet sur le modèle utilisé pour l'étude des goûts légitimes, je ne risquais pas seulement de passer à côté du sujet (au sens où l'entend le profane), mais bien de manquer le topique sociologique du sujet: à savoir la relation entre des contraintes matérielles, liées au niveau de vie et aux conditions de vie (travail, résidence, logement, etc.) et la dimension symbolique de comportements, qui, si directement déterminés qu'ils soient par ces contraintes, peuvent et doivent encore, au même titre que les pratiques "désintéressées " être décrits et interprétés en termes d'attitudes, d'habitudes, de rapport aux pratiques, de "stratégies", de choix - bref de " goûts ». Ainsi, pour prendre un exemple extrême, les " achats de proximité », bête noire et tarte à la crème des études de marché, ne sont pas seulement des routines inscrites dans les dispositions matérielles du milieu; ils ne se comprennent complètement que comme éléments d'un ensemble systématique de choix, plus ou moins forcés, plus ou moins en accord avec le système de dispositions liées à l'origine et à la trajectoire sociales des agents; ils contribuent à façonner des habitudes, elles-mêmes génératrices de nouvelles dispositions, etc.

On ne peut espérer montrer réellement que la culture pratique n'est pas seulement le produit, mais bien l'expression de la « Nécessité » que si l'on consent à taire le détour par l'étude détaillée des contraintes matérielles, contraintes économiques, contraintes écologiques, liées au milieu et au cadre de vie, contraintes biologiques en relation avec les conditions de travail, etc. ; c'est seulement à la condition d'aller le plus loin possible dans cette direction qu'on peut espérer montrer comment les différents groupes aménagent le milieu dans lequel ils vivent en fonction de leurs "goûts » - et réciproquement. Mais il faut sans doute signaler dès maintenant quelques unes des questions que soulève cette démarche. Peut-on autonomiser l'étude des conditions de vie en faisant abstraction, même provisoirement, des relations qu'elles entretiennent avec la position de classe et avec les mécanismes de domination symbolique (tout ce qui se situe sur les flèches D' et B' des schémas de Passeron)? Ne risque-t-on pas de mettre l'accent sur les contraintes du milieu, plus faciles à saisir, plutôt que sur la manière dont les agents jouent avec ces contraintes, et d'aboutir en fin de compte à une sorte de description raisonnée, assez proche de celle qu'un bon informateur, organisé et débrouillard, est en mesure de fournir ? Ne risque-t-on pas d'être conduit à expliquer les pratiques et les goûts matériels par des facteurs matériels et à reconnaître implicitement, du même coup, que l'espace social est discontinu et qu'il faut rechercher des types d'interprétation différents, selon qu'il s'agit de la culture savante ou de la culture pratique, de la culture des classes dominantes ou de la culture des classes dominées? N'est-ce pas revenir, d'une manière détournée, à l'opposition entre le nécessaire et le gratuit, le contraint et le ludique, le besoin et le goût, et admettre, en définitive, que les pratiques utilitaires n'ont de sens que pour les agents, et pas pour le sociologue?

L'ethnocentrisme de classe dont la sociologie légitimiste du goût est constamment menacée ne montre peut-être jamais autant le bout de l'oreille que lorsque le sociologue affiche une propension condescendante à concéder une forme d'autonomie et même d'excellence aux classes populaires, à condition que ce soit dans l'ordre dominé, ou plus exactement extra-culturel, des consommations matérielles et de la satisfaction des 
besoins « primaires ». De ce point de vue, ce qui ne simplifie pas les choses, l'alimentation populaire se prête tout particulièrement à l'alternance du misérabilisme et du populisme dont parlait Passeron. Je me suis efforcé ailleurs de montrer comment on pouvait être tenté de faire correspondre les qualités supposées de la nourriture populaire - «grossière », mais "généreuse ", "substantielle », « authentique », etc. - aux qualités supposées du «Peuple»; facile à développer à partir d'éléments décontextualisés, empruntés à des époques et à des couches sociales différentes, la célébration du goût des classes populaires pour la "bouffe», de l'abondance des nourritures populaires, de la bamboche et de la ripaille - symboles des bons côtés de la «Vulgarité »- constitue un contre-poids populiste tout trouvé à la version misérabiliste de la culture populaire, réduite pour tout le reste à un système de handicaps et d'exclusions.

Peut-être reviendrons-nous sur ces questions dans la discussion qui va suivre ; j'aimerais, pour conclure, montrer comment elles se sont posées sous une forme pratique tout au long de mon travail. Comment, par exemple, fallait-il interpréter les variations statistiques entre les consommations des différents groupes? Devait-on considérer les sous-consommations (et les surconsommations) caractéristiques de l'alimentation populaire (et des différentes variantes de celle-ci) comme des inégalités et des privations liées à des handicaps économiques et culturels, ou comme des " différences ", expression d'habitudes émanant de cultures et de sous-cultures relativement autonomes? Peut-on distinguer deux catégories de consommations, les unes nettement liées à des handicaps, les autres nettement liées à des habitudes culturelles? Comment interpréter ces nonconsommations ou ces non-pratiques qui, selon le point de vue que l'on adopte peuvent être considérées soit comme des exclusions, soit, à l'inverse, comme des refus (et sans doute pas seulement, ou pas toujours, comme des refus contraints, ou des exclusions intériorisées, interdits devenus non-goûts ou dégoûts)? Que faire, par exemple du cas d'un succédané de luxe comme le café soluble, plus cher que le « vrai » café, mais jugé en général « moins bon »? Ne pas pouvoir fréquenter les antiquaires, c'est aussi ne pas avoir à s'encombrer de "vieilleries»; ne pas lire Le Monde ou le Nouvel Observateur, ne pas regarder les émissions « culturelles » ou « intellectuelles » de la télévision, c'est aussi « ne pas se casser la tête", ne pas "perdre son temps" à des choses jugées à la fois ennuyeuses et sans importance. Peut-on se donner un critère permettant de hiérarchiser les pratiques et les goûts sur une échelle unique ou doit-on admettre une pluralité d'échelles de valeurs et de classements, relativement différents selon les groupes? Mais comment réintroduire les points de vue populaires «indigènes " sans régresser en deçà de la rupture avec le relativisme culturel « généralisé » ? Faut-il admettre que les agents sont « relativistes » à l'intérieur d'une structure objective « légitimiste »?

En outre, c'est sans doute à partir des difficultés que rencontre l'interprétation des données empiriques qu'on peut espérer reformuler et dépasser les paradoxes et les apories auxquels aboutit le point de vue légitimiste sur les goûts populaires. Ainsi la question des déterminants négatifs des goûts, des limitations matérielles - en argent, en temps, en distance - qui jouent le rôle de condition nécessaire, de seuil, de butée en deçà desquels la liberté de choisir disparaît ou semble disparaitre prend un tout autre sens lorsqu'elle débouche sur l'étude empirique systématique des relations entre niveau de vie, conditions de vie et mode de vie. Par exemple une bonne manière de rompre avec les stéréotypes relatifs au penchant populaire pour la nourriture est de chercher en dessous de quel seuil de revenu, dans quelles conditions, pour quels groupes l'alimentation est ou devient effectivement une consommation-refuge, une consommation-revanche, 
compensation et substitut de consommations inaccessibles, et inversement dans quelles conditions et par qui elle se trouve elle-même sacrifiée ; c'est en étudiant la structure des budgets familiaux, en s'efforçant d'établir dans quelle mesure et dans quelles conditions (diminution ou augmentation du revenu?) les dépenses alimentaires passent éventuellement après d'autres dépenses, correspondant pourtant à des besoins réputés moins essentiels et moins « vitaux» (comme la voiture, les traites du poste de télévision, etc.) bref en se mettant à l'étude des variations de la hiérarchie sociale des besoins qu'on peut espérer s'affranchir pour de bon des effets souterrains de la croyance dans une hiérarchie « naturelle » des besoins.

J.-C. PASSERON.- Je voudrais poser une question à Grignon à propos des choix de langage : devant tout matériel d'observation et même devant les résultats d'un traitement de données qu'il a lui-même construit et contrôlé, le sociologue prend un risque énonciatif puisque le tableau croisé le plus simple ne dit finalement que ce qu'on est capable d'en dire en langue naturelle. L'interprétation qui passe par le choix des mots est constitutive de toute énonciation sociologique. En choisissant un langage théorique plutôt qu'un autre, on ne décrit plus «les mêmes choses». Quelle a été votre politique de renonciation? Quand vous employez des expressions comme "je devais choisir", «fallait-il décrire ces pratiques en termes de privation, de disparité, d'inégalité ou de différence ", voulez-vous dire que vous aviez une stratégie et des critères constants ?

C. GRIGNON.- Nous savons bien que personne ne peut avoir d'emblée, surtout sur un sujet où on est nécessairement livré aux oscillations dont nous parlons, une véritable « politique » d'énonciation. Je suis parti d'humeurs réactives, de soupçons, d'inquiétudes que je me suis efforcé, au fil des brouillons et des discussions successives, de contrôler et de transformer en schèmes capables de résister aux dérives que j'étais à même de constater. En l'absence d'un paradigme constitué de la sociologie des classes et des goûts populaires, il n'est pas possible de systématiser a priori les stratégies de recherche, encore moins de disposer d'un langage complètement stabilisé.

47 J.-C. PASSERon.- À la lecture de l'article de C. et C. Grignon paru dans la Revue française de Sociologie, j'ai l'impression que vous avez choisi une politique que j'appellerais épistémologique de renonciation: vous vous êtes astreint à parler de l'objet «goûts populaires " en incorporant à la description de l'objet le discours de la construction de l'objet, ce que j'appellerai le discours du parcours. L'oscillation dont nous parlons - par exemple entre populisme et misérabilisme - est non pas maitrisée théoriquement a priori - et comme vous le dites personne ne peut le faire - mais elle est manifestée dans les questions auxquelles elle vous oblige. Les trous de la description et le porte-à-faux de l'analyse engendrés par une démarche qui réduit le sens d'une culture pratique aux nécessités pratiques auxquelles elle se réfère est sans doute ce qui se voit le mieux en acte dans cet article qui incorpore à l'objet la difficulté que posait l'objet.

C. GRIGNON.- Avait-on d'autres moyens, je vous demande un peu, d'objectiver les enjeux théoriques que l'oscillation du discours sur un pareil sujet laisse tout au plus entrevoir par intermittences, et d'en faire partager la conscience, que d'épingler quelques cas flagrants d'impasses, de bévues ou de cécités? naturellement, j’ai reporté à la fin de l'article cet essai de systématisation critique, auquel il ne pouvait être question, dans ces conditions, de donner le statut d'une introduction théorique.

F. DE SINGLY.- Je voudrais poser une question à Grignon sur les méthodes et leur éventuelle spécification en fonction du caractère dominant ou dominé des cultures 
décrites. Peut-on, par exemple, utiliser le questionnaire sans entrer du môme coup dans la logique de la description misérabiliste?

C. GriGnon.- N'y a-t-il pas, dans la question que vous posez, une théorie implicite de la division des tâches et des terrains entre les techniques d'enquête? Dans la mesure où l'on considère qu'il faut autonomiser les cultures populaires pour pouvoir les décrire, où l'on privilégie, à la manière des anthropologues, les situations protégées et «insulaires » de ghetto ou de niche, on risque en effet d'être conduit à se cantonner dans les techniques ethnographiques, à la rigueur l'interview, de préférence les techniques d'observation directe et continue. Ce n'est pas un hasard si l'étude des cultures populaires se trouve reléguée sur le versant ethnologique de l'œuvre de certains sociologues, ou si une description qui prend pour objet exclusif la culture populaire, comme on la trouve chez R. Hoggart, est d'inspiration exclusivement ethnographique. Renoncer à la technique proprement sociologique du questionnaire - même si les risques que vous évoquez sont bien réels - c'est admettre implicitement qu'on peut et qu'il faut faire abstraction, au moins provisoirement, du rapport de domination entre les cultures (ce qui se passe sur l'axe vertical); à la limite, c'est postuler d'avance l'hétérogénéité de l'espace social des goûts et des pratiques. Par ailleurs, si elles ne sont pas très bien adaptées à l'étude interne des cultures populaires, les enquêtes par questionnaire dont je me suis servi (celle que nous avons réalisée à l'INRA et l'enquête annuelle de l'INSEE, qui constitue une référence statistique quasi obligée) permettent au moins d'organiser l'espace social des pratiques alimentaires, de saisir, à grands traits, les relations entre l'alimentation populaire et les alimentations bourgeoise et petite-bourgeoise.

J.-C. PASSERON.- Je ne suis pas tout à fait d'accord avec ce que sous-entend la réponse de Grignon qui donne à penser que tout instrument d'observation sociologique devrait être et rester - bien employé par qui sait l'employer - un instrument "tous terrains". D'accord dans l'éther épistémologique, mais il faut aussi savoir reprendre contact avec le sol rustique de la sociologie du travail sociologique. On ne peut séparer un instrument de recherche des habitudes mentales et sociales que son usage a constituées et qui, en précisant son mode d'emploi, ont fini par s'incorporer à la définition pratique de l'instrument. En droit rien n'empêche de mettre le questionnaire au service d'une récollection de données sur la vie quotidienne des classes populaires, puisque le langage $\mathrm{du}$ questionnement pourrait se faire langue indigène (les "dialectes sociaux" ont maintenant leurs grammairiens) et les items de la description être repensés selon les catégories d'une ethnographie informée de son objet. De même, rien n'empêche en principe d'appliquer la méthode ethnographique à l'observation in vivo de la vie quotidienne des classes dominantes pour saisir de plus près le vernaculaire de leur dialecte et de leur style de vie. En fait, on a tout intérêt à choisir ses instruments d'observation pour ce qu'ils sont, c'est-à-dire pour ce qu'ils font et ont fait observer entre les mains de tout un chacun. Dans une problématique et sur un objet déterminés, il est prudent de choisir les instruments de travail dont l'usage habituel véhicule les chances les plus faibles de volatiliser ou de biaiser l'objet, à moins qu'on ne fasse le pari héroïque de s'obliger à un surcroît de vigilance pour les faire fonctionner en sens inverse de leurs fonctions coutumières. Les instruments font au moins autant faire au sociologue ce qu'ils ont accoutumé de faire que ce que le sociologue croit leur faire faire: il vaut toujours mieux choisir les instruments qui ont confirmé leur aptitude à faciliter le travail de rupture ou de construction qu'on estime le plus urgent, et s'il faut être ici complètement réaliste, conseiller l'instrument capable de faire une partie de ce travail, y compris par ses 
automatismes. Le questionnaire, par exemple, transporte avec lui une invite insistante aux questions et aux formulations que son passé a stabilisées, ne serait-ce que parce qu'il les a étalonnées (on peut s'en détacher) mais surtout toutes les absences de questions qu'il a progressivement constituées en non-faits sociaux: il est plus difficile de lus improviser. Il faut savoir ce que savent à peu près faire les instruments pour ne pas leur demander un travail au-dessus de leurs forces - étant bien entendu, je le sais, que la force méthodologique d'un instrument n'est pas autre chose que celle dont peut s'assurer épistémologiquement son utilisateur. Bref, faire toute sa part à la force d'inertie de l'instrument, c'est aussi, pour le sociologue, ne pas trop présumer de ses propres forces.

C. GRIGNON.- Je pense, comme vous, qu'en pratique, il faut souvent lorsqu'on étudie les classes populaires accorder la préférence aux techniques d'observation ethnographiques, ne serait-ce que parce qu'elles permettent aux sociologues de se familiariser avec un univers social étranger à la plupart d'entre eux. En outre, en ce qui concerne le traitement des données recueillies au moyen du questionnaire, il faudrait encore compter avec ce qui se passe en deçà du langage proprement dit, à l'étape du pré-langage tabulaire : quand on commence à travailler sur un tableau, on met en œuvre des schèmes implicites de classement et de hiérarchisation (ordre des colonnes, des lignes) qui précèdent les choix linguistiques (titrage du tableau, des colonnes, des lignes). Il reste, malgré tout, que l'enquête statistique par questionnaire conserve, dans le cas der pratiques populaires, ses avantages habituels de précision et d'économie ; elle permet, là comme ailleurs, de distinguer entre les groupes, les strates, les fractions, de comparer, bref de mettre en relation les variations des pratiques et la stratification sociale. À ce titre, elle peut permettre à la sociologie des classes populaires de sortir de la monographie et des études de cas ; surtout, elle est un moyen de rompre avec l'illusion, tenace, de l'homogénéité des classes et des cultures populaires. Par ailleurs, rien n'interdit d'adapter et de bricoler ces instrument tous-terrains de manière à ce qu'ils puissent réellement passer partout ; on peut spécifier les questions, les formulations, les techniques de passation, etc. On ne voit pas non plus pourquoi on se priverait dans ce cas des bénéfices de l'emprunt et de la transposition des techniques utilisées d'habitude pour l'étude des classes dominantes; s'agissant de passer d'un terrain au terrain voisin, les risques sont quand même plus limités que lorsqu'on essaie, comme on le fait couramment et à bon droit, d'importer en sociologie les méthodes d'une autre discipline.

Il faudrait aussi parler des biais que ne manquerait pas d'introduire un recours exclusif aux techniques de l'enquête ethnographique. Elles aussi font faire au sociologue ce qu'elles ont accoutumé de faire, et risquent de le transformer en anthropologue à l'ancienne, centré sur l'étude interne des cultures insulaires. L'exemple des études rurales montre que «l'ethnographisme » conduit à privilégier les aspects les plus traditionnels, les plus folklorisables, les plus fermés, les plus exotiques des cultures paysannes. Non que les techniques en elles-mêmes soient en cause : de même que rien n'empêche de poser des questions par écrit sur le tiercé, la belote ou le football, rien n'empêche de faire l'observation directe du ramassage scolaire, des consultations d'un conseiller agricole ou du Salon de l'Agriculture ; mais la tradition de la discipline a toutes les chances d'amener celui qui se saisit de ses outils à laisser de côté les traits « trop » modernes et à manquer les transformations des cultures paysannes ou ouvrières.

54 Ne peut-on craindre, enfin, que l'ethocentrisme se réintroduise par l'intermédiaire du souci légitime de se doter d'instruments appropriés au cas particulier des classes populaires? Changer d'instruments lorsqu'on passe du côté des dominés, n'est-ce pas 
reconnaitre l'existence d'une ligne de démarcation, de ce limes que j'évoquais tout à l'heure? Exclure par principe l'instrument par excellence de l'enquête sociologique, n'est-ce pas une manière d'admettre que les membres des classes populaires « campent en dehors de la société », qu'ils sont les « indigènes d'une culture naturelle »?

J.-C. PASSERON.- Remettons à plus tard la réponse qu'appelle votre soupçon ultime. Mais remarquons dès maintenant que l'existence du rapport de domination oblige la sociologie des cultures populaires à un surcroît d'attention méthodologique lorsqu'elle prend pour informateurs des individus sur qui pèse de façon multiforme ce rapport: la relation sociale qu'instaurent les différentes méthodes d'observation est inégalement proche de celle que les membres des classes populaires ont accoutumé de subir dans presque toutes leurs expériences de dominés. Par-delà la disponibilité technique des instruments de récollection des données aux ré-utilisations novatrices, la situation d'observation qu'ils exigent doit toujours être analysée comme une situation sociale qui conditionne différemment la nature des informations obtenues en fonction des positions respectives des informateurs et de l'observateur.

L'évolution de la méthodologie de W. Labov, depuis les enquêtes de Martha's Vineyard ou de New York City (interviews sur échantillons aléatoires ou raisonnes) jusqu'à l'enquête de Harlem (enregistrement en situation "naturelle " grâce à un jeune informateur noir adopté par le groupe), illustre bien la recherche par le sociolinguiste de la méthode d'observation spécifique appelée par un objet comme les "vernaculaires " populaires et par les hypothèses sur cet objet. Dans l'enquête sur une bande de jeunes vivant dans un ghetto noir, la méthode d'observation (un seul groupe ethnique, dont la production verbale est constamment suivie, un même âge, un style de vie unique) est indissociable de la théorie linguistique qui, s'appuyant sur le constat de l'appartenance de la "variation " au système, rompt avec "l'identification de la structure et de l'homogénéité » et par conséquent avec l'interprétation de la variation en termes de code switching. Faisant l'hypothèse que le "vernaculaire noir américain » (VNA) est un dialecte de l'américain qui peut être décrit connue système phonologique et grammatical au même titre que tout autre système linguistique, Labov a dû progressivement et non sans tâtonnements se donner les moyens de l'observer dans des situations de parole qui restituent à son usage toutes ses fonctions culturelles et sociales: la plupart des relations sociales qu'instauraient les méthodes classiques d'observation et d'enregistrement détruisaient la production verbale qu'il entendait étudier. L'entretien, tel que le pratiquaient les psychologues scolaires, instaurait en effet une relation d'interrogatoire qui, ne pouvant être identifiée que comme relation pédagogique ou policière, ne révélait plus que mutisme, onomatopées ou bribes verbales. C'est une telle méthode d'observation qui autorisait un Jensen - simplificateur imperturbable de Bernstein - à conclure à la " carence » ou au « handicap » verbal, à beaucoup moins qu'un " code restreint », un endeçà de tout langage, de toute grammaticalité, de toute logique.

On voit au passage ce qui fait la différence entre les instruments d'enquête : c'est la relation sociale d'obtention de l'information qu'ils instituent, et non - comme le veut l'identification mécanique du questionnaire à la «méthode quantitative» et de l'observation à la «méthode qualitative »- la plus ou moins grande disponibilité des données recueillies à l'analyse quantitative. Sur le corpus ainsi recueilli par une méthode ethnographique (qui est des plus " participantes » puisqu'elle va jusqu'à la complicité) ce sont des analyses de fréquence d'apparition de traits (effacements, contractions, concordances de négations) ou des croisements statistiques par strates, âges, sous- 
groupes ou situations de parole, aussi bien que des analyses culturelles, rhétoriques ou pragmatiques que réalise Labov. La méthode ethnographique ne s'oppose pas au questionnaire comme une méthode qualitative à une méthode quantitative. Ce qui différencie les méthodes de traitement des faits n'est pas inscrit dans les techniques de récollection des données. L'analyse dite " qualitative » n'est souvent que du raisonnement quantitatif incertain ou inconscient de ses comptages (cf. les "souvent", "dans la plupart des cas ", " presque jamais », etc. des descriptions " qualitatives »). L'analyse dite "quantitative» dissimule, par la disponibilité mécanique des occurrences du questionnaire au traitement statistique que l'information recueillie pose exactement les mêmes problèmes épistémologiques que ceux de l'inventaire ethnographique (celui du langage de description du mode et de ses catégorisations et celui du contrôle de sa constance selon les « informateurs »).

Revenons au problème de "l'affinité élective» entre une méthodologie et une construction d'objet, ou, si l'on préfère, entre un dispositif de prélèvement d'informations et un système d'hypothèses. Dans le cas de la démarche de Labov c'est l'hypothèse de l'autonomie symbolique du monde social de la "culture de rue», autrement dit l'hypothèse qu'il n'est pas besoin d'en sortir pour y trouver tous les éléments permettant de le construire en système (à la fois culturel et linguistique), qui se trouve en affinité avec la méthode d'enquête choisie. Seule l'hypothèse d'autonomie peut justifier la méthode mais, en même temps, la preuve de la fécondité descriptive de cette hypothèse reste à charge de la méthode qui doit réussir à faire voir une structure (un système dont les règles de fonctionnement peuvent être décrites) là où l'ethnocentrisme dominant - tant savant que spontané - ne voyait que retombées incohérentes de la maitrise sporadique et partielle d'autres systèmes linguistiques ou culturels. Le gain descriptif est à la fois rendu possible - et limité - par le fait que l'observation et le travail de construction des faits ne font intervenir ici que les relations résumées par la flèche $B$ du schéma 2. Labov fait sans doute violence à la réalité par cette hypothèse d'autonomisation, en prêtant une totale auto-suffisance symbolique à la culture d'un groupe de pairs qui est à la fois culture d'âge et culture de ghetto : culture transitoire, instable, qui se heurte dans le devenir biographique des adolescents aux rapports de force (par exemple scolaires ou professionnels), elle doit sans doute beaucoup de ses traits aux relations sociales qui la rappellent sans cesse à sa position d'infériorité et qui rendent irréaliste le choix labovien de la comprendre toute entière à partir de sa revendication d'autonomie culturelle. Autrement dit, une telle description qui prend au pied de la lettre la certitude proclamée par les "gars dans le coup» (hips) d'inverser les valeurs dominantes (les "paumés », lames, devenant les «bons" élèves, dotés d'une famille éducogène et promis à l'insertion sociale), n'intègre pas à l'analyse les relations du type B' du schéma 2. Mais le fait est que le rassemblement du matériel culturel et linguistique qui supporte l'opération labovienne de réhabilitation systématique et systémique de la " culture de rue » ne pourrait pas être effectué, et même tout simplement conçu, selon n'importe quelle méthodologie. Plus généralement, il y a bien affinité entre les méthodes qu'appelle l'autonomisation culturelle et le choix de faire abstraction du rapport de domination pour faire "rendre » tout son sens culturel, toute la systématicité dont elle est capable à une culture dominée. Par référence à ce projet, il est vrai que d'autres instruments d'observation seraient impuissants ou même suicidaires en annihilant ce que toute culture dominée ne livre qu'aux méthodes qui savent prendre au mot l'illusion qui fait son ethnocentrisme à elle, l'illusion de l'autonomie absolue. 
59 Exemple a contrario, le recours exclusif à un instrument comme le questionnaire tend toujours par ses exigences de passation comme par la routine et la normalisation des mesures, à constituer les pratiques populaires en pratiques minimales ou déficitaires et, plus grave, de vastes zones de l'univers culturel des classes populaires en non-objet. Non point que ce qu'il mesure comme carence ou distance, lorsqu'il se laisse aller à poser aux pratiques des classes populaires des questions indexées sur les pratiques modales des classes dominantes, ne soit pas mesure de quelque chose : c'est, très exactement, la mesure que justifie l'existence d'un rapport de domination entre classes, c'est-à-dire la mesure que toute une série d'évaluations et de relations sociales, institutionnelles ou non, imposent dans la réalité aux pratiques des classes populaires. Mais on comprend aussi pourquoi le questionnement par questionnaire, qui ne peut en tant que pratique sociologique être complètement dissocié des pratiques sociales la rendant possible, résistera toujours aux redéfinitions subversives visant à décentrer ses questions de celles que lui suggère le rapport de domination symbolique. Ce n'est qu'en lui faisant violence que l'utilisateur d'un tel instrument inventera, péniblement, des questions portant sur les pratiques culturelles proprement populaires; il en trouvera toujours moins, il les catégorisera moins finement ou dans une langue moins adéquate, etc. que celles qui, formulées à partir de traits pertinents dont il a éprouvé et affiné la mesure, conduiront à la multiplication des constats d'infériorité ou d'absence chez les classes populaires : nonréponse ou non-pratique, faible compétence ou faible intérêt.

L'affinité à la fois technique et sociale du questionnaire avec les relations de domination de type A' plutôt qu'avec celles de type B ou B' (schéma 2) se lit en miroir dans ce qu'on pourrait appeler le paradoxe du "questionnaire impossible»: celui qui ne viendrait « raisonnablement » à l'idée d'aucun sociologue - parce qu'il y faudrait une connaissance socialement constituée et méthodologiquement stabilisée de toutes les compétences populaires, autrement dit rien moins qu'une légitimité sociale de l'illégitime - et qui aboutirait à décrire les pratiques des classes dominantes dans les termes de la sociologie négative habituellement réservée aux classes dominées. Vous voyez le résultat, une litanie des privations ou des absences qu'aucune instance sociale ne répertorie comme telles : les membres des classes dominantes ne jouent pas à la belote, à la manille ou à la mourre (ou proportionnellement beaucoup moins souvent), ils ne font pas, ne connaissent pas ceci ou cela, révèlent en ces matières leur gêne, leur incompétence ou leur honte culturelle par les plus forts taux de non-réponse, etc. Cela paraîtrait forcé, idéologique ou factice. Et cela le serait parce qu'une telle sociologie-fiction n'inverserait jamais que mythiquement les flèches D et D' du schéma 2. Il existe sans doute des lieux et des moments sociaux où les expériences correspondant à cette inversion symbolique peuvent devenir réelles: Hoggart décrit par exemple ce retournement de la maladresse sociale et du malaise culturel chez un représentant des middle-classes égaré dans une conversation et une gestuelle populaires à un comptoir de bistrot où la certitude du nombre et l'avantage du terrain mettent momentanément en situation dominante les normes dominées du jeu inter-actionnel. Mais la généralisation sociologique de cette réciprocabilité logique des pratiques dominantes et dominées ne relève que de l'expérience imaginaire ou du propos éthique de réhabilitation envers et contre tout à quoi se reconnaît le populisme qui révèle là son ambiguïté: le populisme n'est pas seulement une ligne politique, c'est la tentation constante de toute description sociologique des classes populaires, qui croit ne pouvoir échapper à l'arbitraire culturel de la domination symbolique qu'en affirmant décisoirement la supériorité des mœurs et 
des compétences dominées (cf. par exemple le dénombrement en forme de faire-valoir des savoir-faire des élèves les plus déshérités, dans Les enfants de Barbiana). Le populisme fait au peuple un coup de Jarnac imparable en ostentant le coup à blanc d'une réciprocabilité des rapports de domination symbolique qui n'a d'autre effet que de détourner la description de ce qui reste solidement non-réciprocable. Ce n'est pas là le chemin par où la sociologie des cultures populaires peut leur faire justice descriptive. Il n'y a pas de raccourcis théoriques au parcours du réseau de relations empiriques qui commandent la description complète des cultures dominées. Ce que ne construit ni n'impose l'ordre social, il faut au sociologue quelque patience théorique et empirique pour le dire.

61 J. PARmentier.- Peut-on réduire le discours des dominants sur la culture dominée au mépris et à la certitude de leur propre valeur universelle ? Il y a quand même des discours dominants qui disent qu' « il y a des choses pas mal dans les cultures populaires », « des choses qu'on n'a pas». On a toujours attribué ce discours à la mauvaise conscience populiste, en particulier celle des intellectuels. Il y a pourtant des cas où la culture dominante s'est réellement enrichie en allant emprunter des traits aux cultures populaires; le discours des dominants exprime aussi parfois la quasi envie, la quasi jalousie, même l'admiration déclarée.

62 I. JonAS.- Le cinéma par exemple, voilà un cas d'art populaire détourné et récupéré par la culture dominante.

63 J.-C. PASSeron.- Laissons le cinéma, et surtout une expression comme celle d'«art populaire » appliquée au cinéma, qui, produit dès l'origine par des professionnels, a toujours eu des publics mêlés, et qu'au moins ses théoriciens ont destiné très tôt à devenir le septième art. Sans entrer dans les problèmes historiques que pose la circulation sociale des formes (musicales, chorégraphiques, littéraires, etc.) ce qui intéresse la description sociologique, c'est la disposition générale que manifestent les dominants lorsqu'ils s'alimentent, que ce soit en tant que producteurs ou que consommateurs, à des cultures populaires. C'est le propre des dominants que de vouloir avoir en même temps le "Même et l'Autre ", et de disposer des moyens de ce caprice. Lorsque les dominants s'aperçoivent dans leurs vagabondages, qu'ayant «tout ce qui compte ", ce qui leur échappe, "ce n'est pas rien ", la captation va de soi ; elle n'est à leurs yeux ni vol, ni récupération, ni même enrichissement ; ils ne font que reprendre ce qui leur appartient de droit. À la sociologie de montrer qu'il subsiste toujours quelque chose de l'encanaillement bourgeois - mais où est la canaillerie ? - dans la subversion surréaliste, l'inversion populiste ou le déplacement poétique. Chez Aragon encore le plaisir de descendre qui doit toujours quelque chose à celui de condescendre, s'énonce en toute ingénuité dans les célébrations conjointes de l'Éphémère et du Pickpocket, à l'occasion d'une virée estivale de jeunes gens « bien » :
«Il existe près des écluses
Un bas quartier de bohémiens
Dont la belle jeunesse s'use
À démêler le tien du mien
En bande on s'y rend en voiture
Ordinairement au mois d'août... »

64 Le rapport de domination symbolique, c'est-à-dire les rapports respectifs des dominants et des dominés à l'exclusion (à ceux qu'ils excluent, à ceux qui les excluent et à ce dont ils sont exclus) n'est jamais symétrique : c'est toujours l'appauvrir que de le traiter comme un simple rapport de différence, ainsi qu'y incite mécaniquement la lecture catégorielle des 
tableaux. Le choix n'est pas entre d'une part la théorie qui place la culture populaire à l'origine de toute création culturelle, dont les productions savantes ne seraient jamais que des ré-élaborations structurales ou des re-définitions fonctionnelles, et d'autre part la théorie pour laquelle toutes les formes de la culture et de l'idéologie circuleraient, comme par gravité, du haut vers le bas, des hauts lieux vers les bas-fonds : pour rendre compte de la complexité des échanges il faut les restituer à un espace de la circulation symbolique qui n'a rien d'une autoroute ou d'une flèche graphique même s'il est irréversiblement polarisé par le rapport de domination. Une culture dominante ne se définit pas d'abord par ce à quoi elle renonce, alors que les dominés ont toujours à faire avec ce que les dominants leur refusent - quoi qu'ils en fassent du reste, résignation, dénégation, contestation, imitation. C'est ce rappel au réalisme de la description qui fait la force de la théorie de la légitimité culturelle connue théorie régulatrice. L'asymétrie des échanges symboliques ne se voit jamais autant que dans le privilège de symétrie dont disposent les dominants, qui peuvent à la fois puiser dans l'indignité culturelle dos pratiques dominées le sentiment de leur propre dignité et dignifier en daignant les emprunter les pratiques indignes, redoublant ainsi, par l'exercice de ce pouvoir de réhabilitation, la certitude de leur légitimité. Pour dire les choses plus crûment, il n'y a pas lieu de décrire comme regard fasciné par la valeur ou la beauté de la culture populaire ce qui n'est jamais chez les dominants que l'exercice d'un droit de cuissage symbolique.

65 C. GRIGNON.- D'accord: la culture dominante n'est pas habitée par ce qu'elle fait à la culture dominée, alors que la culture des dominés est hantée, elle, jusque dans ses moments de répit, par ce que les dominants font aux dominés. Cela dit, eu n'est sans doute pas un des moindres paradoxes de la sociologie de la reproduction que de décrire le travail d'imposition de l'arbitraire culturel accompli en premier lieu par l'École sans jamais en venir à l'étude de ce qui rend ce travail nécessaire, à savoir la capacité de nonreconnaissance des classes dominées (de ce point de vue, la flèche verticale du schéma 2, qui a l'avantage de rappeler le rapport de domination entre les cultures, a peut-être l'inconvénient de présenter celui-ci comme un donné ou un état). Sans se livrer à la célébration naïve de la "résistance populaire " à la domination symbolique (nous reviendrons sur cette question) on peut essayer de décrire le système des protections par défaut, produit et redoublement de la privation culturelle, qui permet aux dominés d'opposer leur «mauvais goût » ou leur "absence de goût» au goût dominant; on pourrait montrer comment ceux-ci savent tirer parti de leur isolement, utiliser la force de l'ignorance et de la méconnaissance, cultiver la mauvaise foi, la cécité, la surdité culturelles, bref faire flèche de tous leurs handicaps pour retourner contre ce qui les exclut l'exclusion dont ils sont victimes. Témoin, pour prendre un exemple consacré par l'usage des séminaires, le « ça m'suffit » faussement modeste des pavillons de banlieue, ou encore la réaction de la petite-bourgeoise provinciale se récriant sur les "sacs à patates " exposés dans les vitrines du Faubourg-Saint-Honoré ou de la rue de Sèvres et leur préférant les «petites robes » faites par sa couturière. En apercevant en même temps les toilettes de luxe et son propre reflet dans la fatale vitrine, la pauvre ne peut pas ne pas ressentir jusqu'à la moelle le frisson de l'indignité culturelle; mais son exclamation ne trahit pas seulement, "dans la logique du ressentiment », la reconnaissance dépitée et déniée de la hiérarchie sociale des goûts; elle exprime aussi la volonté simple et maligne de n'en pas démordre, de choisir ce que l'on a plutôt que ce que l'on vous refuse, bref le réflexe vital de se préférer, quoi qu'il en coûte, à ce qui vous nie, vous et les vôtres. 
De ce point de vue, on peut dire que, dans la lutte symbolique, les dominés ont perdu d'avance, mais que les dominants n'ont jamais partie gagnée, puisque pour gagner il leur faudrait gagner complètement. On trouve de petits signes de la nécessité inhérente à toute légitimité de se faire universellement reconnaitre comme telle aussi bien dans l'irritation des humeurs de droite à la moindre manifestation du «mauvais goût congénital » des classes populaires que dans le prosélytisme des politiques culturelles de gauche acharnées à convertir les niasses à l'art savant. Encore faudrait-il étudier les variations des conditions sociales dans lesquelles se déroule cette lutte. Autre chose, pour les dominés, est de la soutenir en petits bourgeois, chacun pour soi et contre soi, partagés entre le rejet de ce qui vous rejette et la disposition à la révérence culturelle inculquée par l'École, démoralisés par les «modèles » véhiculés par les magazines ou la télévision, et à l'inverse, de pouvoir s'appuyer sur une sous-culture collective, sur le mode de vie, les goûts, les valeurs, la capacité de rappel à l'ordre et de sanction propres à un groupe.

67 J.-C. PASSERon.- La flèche que vous décochez à la flèche du schéma touche juste. Il y a toujours quelque chose du paradoxe zénonien dans une flèche graphique. Identifier la direction d'un vecteur de domination ne nous apprend pas grand chose sur le processus à travers lequel elle s'exerce. La "puissance » (Macht) n'est jamais, comme le rappelait Weber, qu' " un concept sociologiquement amorphe » : c'est dire seulement qu'il y a dans une instance ou dans un groupe pouvoir d'influencer ou d'être obéi ; par quelque moyen que se réalise cette conformité à l'ordre. La sociologie commence lorsqu'on distingue des formes, des instruments et des configurations historiques de la domination. Il y a, par exemple, peu de traits communs entre les rapports de force caractéristiques d'une société féodale, qui, par la distance séparant masses paysannes et couches dirigeantes, par la clarté de la frontière qui sépare, dans toutes les dimensions, dans tous les lieux, et dans tous les moments de la vie sociale dominants et dominés, bref par leur évidence pédagogiqu e font d'eux-mêmes l'essentiel du travail symbolique de domination et, d'autre part, les rapports de force associés aux chevauchements et aux interactions multiples d'une stratification complexe, qui brouillent la perception de la légitimité culturelle et rendent moins immédiate sa reconnaissance par les dominés. C'est dans ce cas de figure qu'apparaît la nécessité d'un travail pédagogique, institutionnel ou non, capable de faire intérioriser aux classes dominées l'illégitimité de leur culture vernaculaire. Moins d'autonomie culturelle pour les classes populaires ne limite pas seulement, comme on se contente d'ordinaire de le constater, les chances de développement et de maintien de formes de culture propre, mais impose aussi aux classes dominantes et aux institutions un alourdissement du travail d'imposition de la légitimité.

\section{NOTES}

1. Karl Marx, L'idéologie allemande, I, « Feuerbach », § 3, Paris, Éditions sociales, p. 75.

2. Ibid., p. 77.

3. Ibid., p. 79.

4. Ibid., p. 78. 
5. P. Bourdieu, J.-C. Passeron, La reproduction, Paris, Minuit, 1970.

6. Cf. E. B. Tylor, Primitive Culture. Researches into the Development of Mythology, Philosophy, Religion, Art, and Custom, Londres, J. Murray, 1871.

7. Sur la distinction entre critères sociologiques et critères culturologiques, cf. H. Maget, «Ethnographie européenne », in J. Poirier, ed., Ethnologie générale, Paris, Gallimard, 1968, p. 1280 sq. (« Encyclopédie de la Pléiade» 24).

8. Cf. P. Bourdieu, « Anatomie du goût », Actes de la Recherche en Sciences sociales, 5, 1976, p. 5-81. 